\title{
Design of an islet-on-a-chip device reveals glucose-stimulated respiration is substrate limited by glycolytic flux through PKM2.
}

\author{
Romario Regeenes ${ }^{1,2}$, Yufeng Wang ${ }^{1,2}$, Anthony Piro ${ }^{1,3}$, Aaron Au ${ }^{2}$, Christopher Yip ${ }^{2}$, \\ Michael B. Wheeler ${ }^{1,3}$ and Jonathan V. Rocheleau ${ }^{1,2,3}$ \\ ${ }^{1}$ Advanced Diagnostics, Toronto General Hospital Research Institute, Toronto, ON \\ ${ }^{2}$ Institute of Biomedical Engineering, University of Toronto, Toronto, ON \\ ${ }^{3}$ Departments of Medicine and Physiology, University of Toronto, ON
}

\section{Abstract}

Pancreatic islets respond metabolically to glucose by closing $\mathrm{K}_{\mathrm{ATP}}$ channels resulting in $\mathrm{Ca}^{2+}$ influx and insulin secretion. Previous work showed that the importance of glycolytic flux in triggering insulin secretion. However, it is unclear whether the triggered ('first phase') secretion is further amplified by $\mathrm{Ca}^{2+}$-stimulation of mitochondrial $\mathrm{NADH}$ production and/or oxidative phosphorylation (OxPhos). To tease apart the metabolism of first phase glucose-stimulated insulin secretion, we designed an islet-on-a-chip microfluidic device to simultaneously measure $\mathrm{O}_{2}$-consumption rate (OCR) and $\mathrm{Ca}^{2+}$-activity of individual islets with high temporal resolution. We used finite element analysis to optimize the placement of sensor in optically clear microwells on a thin glass coverslip. The microfluidic channels were subsequently fabricated using $\mathrm{O}_{2^{-}}$ impermeable plastic to limit outside-in diffusion and push islets in the device against the microsensor. We validated our device using living mouse islets and well-established modulators of respiration. By inhibiting glycolysis and mitochondrial pyruvate transport, we showed islet OxPhos is limited by substrate-NADH rather than ADP in low and high glucose. We subsequently imaged glucose-stimulated OCR and $\mathrm{Ca}^{2+}$-influx simultaneously to reveal a biphasic respiratory response that is determined by glycolytic flux through pyruvate kinase (PKM2) and independent of $\mathrm{Ca}^{2+}$. Ultimately, we validated our device and successfully used it to show islet $\mathrm{OxPhos}$ is determined by glycolytic flux and not amplified by $\mathrm{Ca}^{2+}$-activity.

\section{Significance}

Loss of the first phase glucose-stimulated insulin secretion is one of the earliest signs of Type 2 diabetes (T2D). Revealing the mechanisms that trigger and amplify first phase insulin secretion from pancreatic islets could lead to strategies to mitigate the onset of T2D. In this study, we designed an islet-on-a-chip microfluidic device to measure $\mathrm{O}_{2}$-consumption rate and $\mathrm{Ca}^{2+}$ activity of individual islets dynamically through first phase secretion $(<5 \mathrm{~min})$. Our data show first phase islet respiration is limited by glycolytic production of pyruvate independent of $\mathrm{Ca}^{2+}$ influx.

\section{Author contributions}


R.R., Y.W. and J.V.R. designed research; R.R. and Y.W. performed research; A.P. and M.B.W. provided tissue; A.A. and C.Y. provided technical assistance, R.R., Y.W., and J.V.R. wrote the paper.

\section{Keywords}

Islet-on-a-chip, microfluidics, pancreatic islets, widefield imaging, oxygen sensor, oxygen consumption rate, seahorse assay, mouse islets, Stern-Volmer.

\section{$\underline{\text { 2. Introduction }}$}

Glucose-stimulated insulin secretion (GSIS) occurs from pancreatic islets in a large first phase burst followed by smaller second phase oscillations [1] [2]. Critically, first phase insulin secretion is lost at the earliest signs of type 2 diabetes (T2D) [3] suggesting the metabolism behind the stepped response to glucose is mechanistically linked to the disease.

GSIS is triggered from islet beta-cells by a rise in ATP/ADP ratio that closes $\mathrm{K}_{\mathrm{ATP}}$ channels resulting in membrane depolarization and $\mathrm{Ca}^{2+}$-influx (termed ' $\mathrm{K}_{\mathrm{ATP}}$-dependent secretion') [4] [5]. Early work revealed a central role for glycolysis in triggering insulin secretion [6] [7]. More recent work showed that inhibition of pyruvate kinase-M2 (PKM2) (i.e., the last step of glycolysis) abolishes insulin secretion suggesting glycolysis-derived pyruvate is also a prerequisite to trigger insulin secretion [8]. Insulin secretion is further amplified by glucosemetabolism independent of $\mathrm{K}_{\mathrm{ATP}}$ channel activity (termed ' $\mathrm{K}_{\mathrm{ATP}}$-independent amplification') effectively doubling insulin secretion [9] [10]. The amplification of second phase insulin secretion has been classically linked to mitochondrial anaplerosis and associated efflux of metabolic intermediates [11] as well as to $\mathrm{Ca}^{2+}$-induced mitochondrial metabolism and respiration [12] [13]. Whether these same mechanisms also amplify first phase insulin secretion is less defined. For example, activation of PKM2 was recently shown to enhance second phase insulin secretion from islets without impacting first phase insulin secretion [14].

It is well recognized that mitochondrial metabolism and OxPhos are key determining factors of GSIS that are significantly impaired in T2D [15] [16]. $\mathrm{O}_{2}$-consumption rate (OCR) has been suggested to be the most informative parameter of mitochondrial function and cellular metabolism as it reveals electron transport chain (ETC) function and substrate supply as well as others [17]. Thus, measuring OCR could help reveal the metabolism of first phase insulin secretion. The lack of studies on $\mathrm{K}_{\mathrm{ATP}}$-independent amplification of first phase insulin secretion could be partly due to technological limitations of simultaneous measuring OCR (related to OxPhos) and $\mathrm{Ca}^{2+}$ (insulin secretion triggering and mitochondrial activation). Specifically, such measurements need high temporal resolution, since glucose-stimulated metabolism related to first phase insulin secretion occurs within 5 minutes. For example, Patterson et al. used twophoton $\mathrm{NAD}(\mathrm{P}) \mathrm{H}$ imaging to show a two-step rise in glucose-stimulated islet $\mathrm{NAD}(\mathrm{P}) \mathrm{H}$ response; however, due to the short time-lag between the steps $(<20 \mathrm{~s})$, they suggested that the second step was not triggered by $\mathrm{Ca}^{2+}$-influx but by the regulated entry of pyruvate into mitochondria [18]. In addition, these simultaneous measurements should ideally be performed on single islets to avoid blurring of the temporal responses due to islet-to-islet variability [19].

Our goal was to simultaneously measure $\mathrm{OCR}$ and $\mathrm{Ca}^{2+}$ activity from individual islets with sufficient temporal resolution to distinguish their first phase glucose responses. For example, 
sensing glucose-stimulated $\mathrm{Ca}^{2+}$-influx prior to a rise in OCR would be consistent with $\mathrm{Ca}^{2+}$ stimulated mitochondrial metabolism. Different methods are commercially available to measure islet respiration. However, these methods often do not provide optical access to simultaneously measure $\mathrm{Ca}^{2+}$ activity, and when they do, they lack the spatial and temporal resolution to measure individual islet responses [19] [20]. To address these limitations, we aimed to place an optical $\mathrm{O}_{2}$ sensor inside microfluidic devices previously designed for quantitative live cell imaging of pancreatic islets [21] [22] [23]. These devices hold the islets directly against a thin glass coverslip, which here provides an ideal location for the placement of optical sensors. By placing the $\mathrm{O}_{2}$ sensor in optically clear yet $\mathrm{O}_{2}$-impermeable microwells, we achieved the sensitivity to measure OCR from individual pancreatic islets and the ability to simultaneously image $\mathrm{Ca}^{2+}$-influx. Finally, we used this device to show first phase respiration is NADHsubstrate limited by glycolytic flux and independent of $\mathrm{Ca}^{2+}$ activity.

\section{Experimental}

\section{Pancreatic islet isolation and culture}

Animal procedures were approved by the Animal Care Committee of the University Health Network, Toronto, Ontario, Canada in accordance with the policies and guidelines of the Canadian Council on Animal Care (Animal Use Protocol \#1531). Pancreatic islets were isolated from C57BL/6 male mice (12-14 weeks of age). A solution of collagenase type-V $(0.9 \mathrm{mg} / \mathrm{mL})$ in RPMI-1640 media supplemented with BSA $(0.5 \mathrm{mg} / \mathrm{mL})$ was prepared for islet isolation. Mice were anesthetized with isoflurane and sacrificed via cervical dislocation, and perfusion of the pancreas was performed via injection of $3 \mathrm{~mL}$ collagenase type-V solution in the common bile duct with a $30 \mathrm{G}$ needle, inserted in the direction of liver to pancreas (common bile duct sutured at small intestine). Following successful perfusion, the pancreas was removed and placed in a 50 $\mathrm{mL}$ conical tube containing an additional $3 \mathrm{~mL}$ of the collagenase type- $\mathrm{V}$ solution. Pancreases in conical tubes were incubated in a water bath at $37^{\circ} \mathrm{C}$ for $11-12$ minutes and mechanically disrupted via light shaking until exocrine pancreas was fully digested and the solution was homogenous with digested tissue. Finally, digestion was inhibited via addition of $45 \mathrm{~mL}$ islet culture media (RPMI medium 1640 (Sigma-Aldrich) supplemented with $11 \mathrm{mM}$ glucose, 10\% FBS, $5 \mathrm{U} / \mathrm{ml}$ penicillin-streptomycin, and $20 \mathrm{mM}$ HEPES). Under a dissection microscope, islets were separated from digested exocrine pancreas material and incubated in islet culture media in a humidified incubator at $37^{\circ} \mathrm{C}$ and under $5 \% \mathrm{CO}_{2}$ overnight.

\section{Microfluidic device fabrication}

The custom microfluidic device comprised a 'top piece' and glass coverslip with $\mathrm{O}_{2}$-sensor microwells. The top piece with $80 \mu \mathrm{m}$ tall channels and $60 \mu \mathrm{m}$ tall dam-wall was fabricated using $3 \mathrm{~mm}$ thick PMMA and a Nomad 883 Pro to mill the channel. The channel dimensions were modelled in AutoCAD 2021, and then imported into Carbide Create V5 to create the GCode necessary to run the CNC mill. A 1/16" endmill was used to mill the device followed by a $1 / 8 " \mu \mathrm{m}$ endmill for the inlet and outlet ports. The top piece was washed in a $70 \%$ ethanol solution and left to dry before attachment to the microwell coverslip. The $\mathrm{O}_{2}$-sensor microwells were fabricated onto no. 1 glass coverslips using SU-8 photoresist (Micro-Chem) exposed through a transparent plastic film. The $10 \mu \mathrm{m}$ tall microwells in the final design were $10 \mu \mathrm{m}$ in 
diameter and $20 \mu \mathrm{m}$ in pitch size. The $\mathrm{O}_{2}$-sensor was prepared by mixing PDMS (10:1 ratio) and PtTFPP $(0.1 \mathrm{mg} / 1 \mathrm{~mL}$ in toluene) at a volume ratio of 10:1 [24]. $100 \mu \mathrm{L}$ of this mixture was left to dry for $30 \mathrm{~min}$ prior to being squeegeed into the microwells. The slide was subsequently left to dry in the dark for 24 hours at room temperature. Prior to use, the microfluidic device and glass coverslip with $\mathrm{O}_{2}$-sensor microwells was carefully assembled using epoxy-based glue and clamped together for 1 hour.

\section{Microfluidic fluid flow modelling/Oxygen Sensor}

The device was constructed in two-dimensions using AutoCAD 2020 prior to being extruded to three-dimensions in COMSOL Multiphysics 5.4 (COMSOL). Pancreatic islets were modelled as $120 \mu \mathrm{m}$ radii cylinders with the circumferential edge filleted and modeled to consume $\mathrm{O}_{2}$ under a maximum rate of $0.034 \mathrm{~mol} \cdot \mathrm{s}^{-1} \cdot \mathrm{m}^{-3}$ [25]. To determine $\mathrm{O}_{2}$-concentration underneath the islet a cut line surface normal was used with the same coordinates for all the simulations. Inlet pressure for all the simulations was set to $0 \mathrm{kPa}$ while the exit flow rate was set to $200 \mu \mathrm{L} \mathrm{h}^{-1}$, unless otherwise stated. The simulated models had meshes with 50735-174199 domain elements, 11221-14864 boundary elements, and 818-11184 edge elements. All diffusion coefficients were used at $37^{\circ} \mathrm{C}$ for our numerical simulations.

\section{Microscope Setup}

Luminescence and fluorescence imaging was done using the 40×/0.75 NA air objective of an inverted widefield RAMM fluorescence microscope (ASI) equipped with 3 LEDs (460, 535, and $560 \mathrm{~nm}$ ), stage top incubator (Okolab) and Iris 15 sCMOS camera (Photometrics). The microscope was controlled using MicroManager [26]. PtTFPP luminescence was excited using two to three $500 \mathrm{~ms}$ bursts of the $535 \mathrm{~nm}$ LED and collected through the 590-660 nm band-pass emission filter. Cal-520 fluorescence was excited by a $300 \mathrm{~ms}$ of the $465 \mathrm{~nm}$ LED attenuated to $32 \%$ using a neutral density filter and collected using a 495-525 nm band-pass emission filter. Images consisted of $1264 \times 740$ pixels sized at $0.425 \mu \mathrm{m} /$ pixel after $4 \times 4$ pixel binning.

\section{Sensor Calibration}

The PMMA device with $\mathrm{O}_{2}$-sensing microwells was subjected to flowing solutions of $20 \%$ (air saturated $\mathrm{ddH}_{2} \mathrm{O}$ ) and $0 \%\left(10 \%\right.$ sodium sulfite) $\mathrm{O}_{2}$. The PtTFPP was imaged to measure individual microwell mean intensity. The mean intensities at $20 \%$ and $0 \% \mathrm{O}_{2}$ were used to calculate the Stern-Volmer constant, $\mathrm{K}_{\mathrm{Sv}}$. The mean luminescence intensity versus $\mathrm{O}_{2}$ concentration was modelled as a linear regression using the Stern-Volmer equation (Eq. 1):

$$
\frac{I_{0}}{I}=1+K_{S V} *\left[O_{2}\right]
$$

where $I_{0}$ and $I$ are the luminescence intensity in the absence and presence of molecular oxygen, $\left[\mathrm{O}_{2}\right]$.

\section{Glucose stimulated oxygen imaging}

Freshly isolated islets were pre-incubated for $1 \mathrm{hr}$ in $\mathrm{BmHH}$ imaging buffer $(125 \mathrm{mM} \mathrm{NaCl}, 5.7$ $\mathrm{mM} \mathrm{KCl}, 0.42 \mathrm{mM} \mathrm{CaCl}_{2}, 0.38 \mathrm{mM} \mathrm{MgCl}_{2}, 10 \mathrm{mM}$ HEPES, and 0.1\% BSA; pH 7.4) with $2 \mathrm{mM}$ 
glucose at $37^{\circ} \mathrm{C}$. Islets ( 2 to 5 at a time) were subsequently loaded into the stage-mounted microfluidic device at $37^{\circ} \mathrm{C}$ and maintained in $200 \mu \mathrm{L} / \mathrm{ml}$ of flowing media using pull from a syringe pump. The islets were exposed to various treatments as indicated by exchange of the media in an on-chip well prior to imaging the PtTFPP luminescence.

\section{Simultaneous OCR- and $\mathrm{Ca}^{2+}$-imaging}

To simultaneously image OCR and $\mathrm{Ca}^{2+}$-activity, mouse islets were incubated for $1 \mathrm{hr}$ at $37^{\circ} \mathrm{C}$ in $\mathrm{BmHH}$ with $4 \mu \mathrm{M}$ Cal-520 (Life Technologies), $2 \mathrm{mM}$ glucose, and $1 \mathrm{mM}$-acetylcysteine (NAC) [27]. The islets were subsequently loaded into the stage-mounted microfluidic device at $37^{\circ} \mathrm{C}$ and pre-incubated in $200 \mu \mathrm{l} / \mathrm{hr}$ of flowing BMHH (2 mM glucose, $1 \mathrm{mM}$ NAC) for 10 minutes prior to imaging. A custom macro was created to collect PtTFPP and Cal-520 images using 535 and $460 \mathrm{~nm}$ excitation, and at two different z-planes to account for the difference in imaging plane between the microwells and Cal-520 loaded islets. The islets were then variably treated as indicated by replacing media in the on-chip well while imaging.

\section{Image analysis}

PtTFPP luminescence and Cal-520 images were analyzed using ImageJ. Regions of interest (ROI) were manually drawn around each microwell underneath the islet as well as microwells loaded with only PDMS for background correction. After selection, the mean intensity for each microwell was recorded after background correction. The $\mathrm{O}_{2}$-concentration in each microwell was subsequently determined using the $\mathrm{K}_{\mathrm{SV}}$ of the calibrated sensor and Eq. 1. Lastly, OCR was calculated as the change in $\mathrm{O}_{2}$-concentration multiplied by the volumetric flow rate across the islet, approximating islet volume to be a cylinder or sphere. The dissolved $\mathrm{O}_{2}$-concentration at 37 ${ }^{\circ} \mathrm{C}$ was calculated to be $207.3 \mu \mathrm{M}$. $\mathrm{Ca}^{2+}$ images were analyzed by normalizing the fluorescence intensity of randomly selected ROIs by the mean intensity during $2 \mathrm{mM}$ glucose treatment.

\section{Results}

\section{Design and optimization of an islet-on-a-chip device with modular $\mathrm{O}_{2}$-sensors}

We recognized that the coverslip of our islet-on-chip microfluidic devices would provide proximity to the tissue and optimal optics to place optical $\mathrm{O}_{2}$-sensors [21] [22] [23]. To explore placing the sensor in $\mathrm{O}_{2}$-permeable substrate underneath islets, we modelled $\mathrm{O}_{2}$-diffusion and OCR by islets in a dam-wall microfluidic device (Fig. 1). We chose an islet-on-a-chip device that traps islets in flowing media using a drop in channel height (e.g., 80 to $20 \mu \mathrm{m}$ ) (Fig. 1A). The drawing (not to scale) shows a device fabricated out of $\mathrm{O}_{2}$-impermeable PMMA (grey) with PtTFPP sensor embedded inside $\mathrm{O}_{2}$-permeable PDMS (yellow) coating the glass coverslip. We normally fabricate microfluidic channels out of PDMS but switched to PMMA to avoid swamping/masking islet $\mathrm{O}_{2}$-consumption. We modelled both an empty device (left) and isletfilled-device (right) using finite element analysis to determine $\mathrm{O}_{2}$ concentration in the sensor layer (Fig. 1B) including along the centerline plotted from left to right with the flow (Fig. 1C). These data show very little difference in the $\mathrm{O}_{2}$ underneath islets (right image, red and blue circles), which is consistent with diffusion along the PDMS substrate dampening the sensor response to islet respiration. To maximize sensor response, we subsequently modelled placing 
the sensor inside microwells (Fig. 1D-H). The drawing (not to scale) depicts microwells formed using $\mathrm{O}_{2}$-impermeable SU-8 (black) to limit diffusion between the microwells (yellow) (Fig. 1D). To determine the impact of microwell size, we modelled the OCR of islets placed against microwells of varying widths $(10,50$ and $100 \mu \mathrm{m})($ Fig. 1E-F). These data show progressively larger responses to islet OCR with smaller microwell width. Of all well sizes examined, the 10 $\mu \mathrm{m}$ wide wells with $20 \mu \mathrm{m}$ pitch were the most sensitive to the islet OCR. To determine the optimal dimensions, we also simulated $10 \mu \mathrm{m}$ wide microwells with varying depths $(10,30$ and $60 \mu \mathrm{m})$ (Fig. 1G-H). These data show no difference in the response based on the depth of the microwell. Thus, we chose to fabricate microwells that are $10 \mu \mathrm{m}$ wide with $20 \mu \mathrm{m}$ pitch due to sensor response and chose the shortest microwell height $(10 \mu \mathrm{m})$ to minimally affect optical clarity.

\section{Determining factors that affect sensitivity of $\mathbf{O}_{2}$-sensors}

To evaluate potential factors that could affect $\mathrm{O}_{2}$ sensitivity, we modelled varying flow rates, islet proximity and islet $\mathrm{O}_{2}$ consumption rates (Fig. 2). Flow rate is a key factor to consider with the PMMA fabrication since it is the sole source of replenishing $\mathrm{O}_{2}$ inside the channel. Modelling various flow rates through the device showed only a moderate impact on $\mathrm{O}_{2}$ sensitivity (Fig. 2A). These data suggest slower flow rates marginally enhance $\mathrm{O}_{2}$-sensor responses, but the difference is small suggesting sensing would be stable even during fluctuations in flow. Our dam-wall design can optimally trap two different sized islets; $\sim 20 \mu \mathrm{m}$ diameter under the dam-wall, and $>80 \mu \mathrm{m}$ diameter in the channel. Although islets sink, we were concerned that this arrangement could result in some islets not being uniformly pressed against the microwells. To evaluate the effect of proximity, we simulated islets at various heights relative to the microwells (Fig. 2B-C). These data show a less dynamic sensor response with increasing distance between the islet and microwell suggesting close tissue proximity is essential for sensitivity. We also considered different OCR values since islets are normally studied in low and high glucose conditions. We modelled 2- and 20-mM glucose-stimulated OCR by changing the inward flux values of the islet walls. The goal was to determine if there was a visible difference between both treatments (Fig. 2D). It revealed a $12.8 \%$ difference which could be empirically measured. These data suggest relative OCR induced by 2 - and $20-\mathrm{mM}$ glucose will be detected by the sensor (Fig. 2E).

\section{On-chip characterization of the $\mathrm{O}_{2}$ sensor}

$\mathrm{O}_{2}$ sensors are generally calibrated prior to use so that luminescence intensities can be related back to $\mathrm{O}_{2}$ concentrations based on the Stern-Volmer relationship [28]. To determine our sensor dynamic range, we flowed double distilled water $\left(\mathrm{ddH}_{2} \mathrm{O}\right)$ and an $\mathrm{O}_{2}$-scavenger $(10 \%$ sodium sulfite) to obtain luminescence intensities for $100 \%$ air saturated and $0 \% \mathrm{O}_{2}$, respectively (Fig. 3A). These images show an $\sim 25$-fold change in intensity of the microwells in the presence of an $\mathrm{O}_{2}$-scavenger. Based on linear regression, we calculate a $\mathrm{K}_{\mathrm{SV}}$ of $113.3 \pm 0.9196 \mathrm{~L}^{*} \mathrm{mmol}^{-1}$, which is consistent with literature values for this type of sensor, albeit larger than existing sensors (Fig. 3B) [29]. To determine the temporal resolution of the $\mathrm{O}_{2}$-sensor, we measured the response times of the microwells upon switching from $\mathrm{ddH}_{2} \mathrm{O}$ to $10 \%$ sodium sulfite and vice versa (Fig. 3C and D). Response time, $\mathrm{t}_{95}$, is defined as the time required to reach $95 \%$ of the 
luminescence maximum or minimum. These data show a sensor $t_{95}$ switching from $0 \%$ to $100 \%$ air and vice versa of $12.4 \pm 0.7 \mathrm{~s}$ (Fig. 3C), and $4.2 \pm 0.2 \mathrm{~s}$ (Fig. 3D). These times reflect a 0.21 $\mathrm{mM}$ change in dissolved $\mathrm{O}_{2}$ suggesting we should expect much faster response times with the nanomolar changes induced by living islets.

\section{Imaging OCR in individual pancreatic islets}

We subsequently loaded living mouse pancreatic islets in our device to measure the dynamics of OCR (Fig. 4). Once loaded, islets sitting on the microsensor could be imaged by an inverted widefield epifluorescence microscope consistent with the optical transparency of the device (Fig. 4A, top). Islet bioenergetics are commonly measured in batch ( 70 islets $)$ using commercially available devices (e.g., Seahorse XF analyzer) and a series of mitochondrial respiration treatments including: (i) $2 \mathrm{mM}$ glucose to measure basal OCR, (ii) $20 \mathrm{mM}$ glucose to measure glucose-stimulated OCR, (iii) oligomycin to measure ATP-linked respiration, (iv) FCCP to measure maximal respiratory capacity, and (v) rotenone + antimycin to define non-mitochondrial respiration. To validate our device, we used these same treatments on individual islets (Fig. 4A, bottom). The microsensors underneath the islet showed clear changes in luminescence intensities reflecting their respective measurements of $\mathrm{O}_{2}$. These data show that the $\mathrm{O}_{2}$ sensor can measure pharmacologically induced changes in OCR in individual pancreatic islets. However, unlike commercial assays, we are not limited to a narrow size of islets [19] (Fig. 4B). To determine the effect of variable islet size on the OCR, we plotted the basal OCR relative to islet volume estimated from the widefield image (Fig. 4C). These data show a linear relationship between islet volume and OCR $\left(\mathrm{R}^{2}=0.79\right)$ suggesting the responses should be normalized to islet volume. We therefore normalized the individual islet responses to the islet volumes prior to plotting the responses to the respiratory inhibitors (Fig. 4D). These data show a 2-fold increase from basal to glucose-stimulated OCR and maximal respiration consistent with responses from batch analysis using commercially available instruments [19] (Fig. 4E). These data also show proton leak is approximately $68 \%$ of basal OCR consistent with previous studies [30]. Overall, these data validate that our device can measure the OCR of individual pancreatic islets.

\section{Temporal imaging of the glucose-stimulated $\mathrm{OCR}$ and $\mathrm{Ca}^{2+}$ responses}

Glucose-stimulated OCR has previously been shown to rise prior to $\mathrm{Ca}^{2+}$-influx suggesting that $\mathrm{Ca}^{2+}$ does not play an immediate role [31]. To determine the temporal contribution of $\mathrm{Ca}^{2+}$ to glucose-stimulated metabolism, we loaded mouse pancreatic islets with Cal-520 to simultaneously image OCR and $\mathrm{Ca}^{2+}$ activity in response to glucose (Fig. 5A and $\mathbf{B}$ ). The $\mathrm{Ca}^{2+}$ traces upon glucose stimulation show a characteristic 'phase 0' drop upon glucose stimulation due to activation of $\mathrm{Ca}^{2+}$-ATPase ER pump efflux and 'phase 1' rise $\sim 3$ min after stimulation due to voltage-gated $\mathrm{Ca}^{2+}$ channel influx (Fig. 5B). Notably, the glucose-stimulated OCR traces were biphasic showing a rise simultaneously with the drop in Phase $0 \mathrm{Ca}^{2+}$ and a second rise near or before phase $1 \mathrm{Ca}^{2+}$-influx. To determine the magnitude of the OCR responses, we calculated the normalized OCR area under the curve (AUC) for phase 0 and phase 1 as defined by the $\mathrm{Ca}^{2+}$ traces (Fig. 5C and D). In other words, we used the changes in $\mathrm{Ca}^{2+}$-activity to define the $2 \mathrm{mM}$ glucose, phase 0, and phase 1 regions for each OCR trace (Fig. 5C). Using this criterion, the OCR increased significantly and sequentially from basal to phase 0 and to phase 1 (Fig. 5D). To 
further explore the biphasic OCR response, we focused on the relative changes in OCR within the first two minutes of phase 0 and phase 1 by setting "Time 0 " for each curve based on the inflection points of the $\mathrm{Ca}^{2+}$ traces (Fig. 5E and F). Due to variability in the timing of the responses, this analysis could only be done due to our ability to measure traces from individual islets. The first rise in OCR occurs simultaneously with the phase 0 drop in $\mathrm{Ca}^{2+}$ plateauing within $1 \mathrm{~min}$ and prior to phase $1 \mathrm{Ca}^{2+}$-influx (Fig. 5E). These data are consistent with an increase in OxPhos due to the metabolic flux (supply) that is independent of mitochondrial stimulation by $\mathrm{Ca}^{2+}$. The initial plateau was followed by a second rise in OCR that preceded $\mathrm{Ca}^{2+}$-influx (Fig. 5F). Further analysis of the OCR curve using linear regression of the eight time points starting from time $=0 \mathrm{~min}$ fit to an $\mathrm{x}$-intercept of $-28 \pm 20 \mathrm{~s}$. In other words, the second OCR response preceded $\mathrm{Ca}^{2+}$-influx by $\sim 28 \mathrm{~s}$. To further confirm the biphasic OCR response to glucose, we determined the slope of OCR responses for each trace before and after the $-30 \mathrm{~s}$ inflection point (Fig. 5G). These data show significantly different slopes once again are consistent with a further inflection in OxPhos. Overall, these data illustrate that islet respiratory response to glucose is biphasic with the step in the response occurring before and independently of $\mathrm{Ca}^{2+}$-influx.

\section{PKM2 is responsible for the biphasic rise in OCR}

The rate of OxPhos depends on the metabolic supply of NADH ('substrate limited') or when NADH is in excess by the availability of ADP ('ADP limited') (Fig. 6A). We postulated that the biphasic glucose-stimulated OCR response reflects islets in a substrate limited state with transitions in OCR reflecting greater production of NADH by glycolysis and the TCA cycle. To first confirm islet OCR is substrate limited at low glucose, we measured the OCR response of islets in low glucose to inhibition of glycolytic flux using 2-deoxyglucose (2DG) and in response to blocking entry of pyruvate into mitochondria using UK5099 (Fig. 6B). These data show 2DG did not induce a change in OCR consistent with low glycolytic flux in glucose below the Km for glucokinase. However, UK5099 induced a small but significant decrease in OCR indicating that basal respiration is dependent on pyruvate entry. These data highlight the importance of pyruvate entry into the TCA cycle in stimulating OxPhos ( $3 \mathrm{NADH} /$ pyruvate) and potentially reflect flux of amino acid oxidation (e.g., alanine, serine). To confirm that glucose-stimulated OCR is due to glycolytic flux and substrate limited, we measured the OCR response of glucose-stimulated islets to 2DG (Fig. 6C and D). These data show that glucose-stimulated OCR dropped to basal (low glucose) levels by inhibition of glycolytic flux again suggesting the respiratory transition of islets ultimately depends on substrate supply. Due to the varied 2DG and UK5099 responses in low glucose, we speculated that the biphasic nature of the glucose-stimulated OCR reflects downstream regulation of PKM2, which is allosterically regulated by the glycolytic intermediate fructose 1,6-bisphosphate (FBP) [32]. To investigate the role of PKM2 in setting basal OxPhos, we measured the OCR of islets treated with PKM2 activator TEPP-46 for $1 \mathrm{hr}$ (Fig. 6E). These data show a small but significant increase in basal OCR induced by PKM2 activation again consistent with OCR being substrate limited (in this case by the supply of pyruvate from glycolysis). To further investigate the role of PKM2 activity in the glucose-stimulated response, we measured the glucose-stimulated OCR response of TEPP-46 treated islets (Fig. 6F). The higher basal OCR in the presence of TEPP-46 is followed by a sharp decrease induced by glucose. This rapid reduction in OCR is consistent with the rapid entry of pyruvate due to fully active PKM2 leading to lower NADH induced by lactate dehydrogenase activity, conversion to 
oxaloacetate/malate through pyruvate carboxylase activity, and/or depolarization of mitochondrial membrane potential. Notably, the OCR steadily increases out to $15 \mathrm{~min}$ of stimulation with no sign of a biphasic response. In other words, the biphasic glucose-stimulated response observed in untreated islets is replaced by a single faster rise. To determine the role of $\mathrm{Ca}^{2+}$-influx in this response, we simultaneously imaged the glucose-stimulated OCR and $\mathrm{Ca}^{2+}$ responses of TEPP-46 treated islets (Fig. 6G). These data again show a sharp drop in OCR that coincides with the beginning of phase $0 \mathrm{Ca}^{2+}$-efflux followed by a linear rise in OCR that noticeably precedes phase $1 \mathrm{Ca}^{2+}$-influx. Normalizing the curves from several islets relative to glucose arrival showed the linear increase in OCR precedes $\mathrm{Ca}^{2+}$-influx by $\sim 3.2 \mathrm{~min}$ (Fig. $6 \mathbf{H}$ ). Collectively, these results confirm islet OCR is substrate-limited by glycolytic flux and suggest that PKM2 plays a critical role in regulating glucose-stimulated OCR.

\section{Discussion}

In this study, we redesigned a dam wall microfluidic device to hold pancreatic islets directly against $\mathrm{O}_{2}$-microsensors to simultaneously image $\mathrm{OCR}$ and $\mathrm{Ca}^{2+}$ activity. We digitized the sensor in microwells to gain spatial resolution sufficient to measure the responses of individual islets. Our measurements of basal OCR showed that islet responses should be normalized to islet size to reduce variability. Our measurements with respiratory chain inhibitors further validated the method by showing similar responses when comparing bulk assays to the pooled individual islet responses. The optical clarity and fabrication of the microwells using a thin glass coverslip allowed us to image glucose-stimulated OCR and $\mathrm{Ca}^{2+}$-activity. These data revealed a biphasic respiratory response to glucose with an inflection point determined by PKM2 activity and independent of $\mathrm{Ca}^{2+}$-influx. Overall, our data are consistent with first phase glucose-stimulated OxPhos being NADH-substrate limited by glycolytic flux.

Our microsensors are sensitive to nanomolar changes in $\mathrm{O}_{2}$, show fast response times $(<15 \mathrm{~s})$ and are easy to calibrate. To achieve these characteristics, we embedded optically responsive sensor (PtTFPP) within an $\mathrm{O}_{2}$ permeable substrate (PDMS) based on previous work showing this combination had high photostability, large stokes shift and dynamic response [33] [24]. Conventional optical $\mathrm{O}_{2}$ sensors for microfluidic devices are generally planar and open to the environment. Our initial modelling suggested that $\mathrm{O}_{2}$ diffusion inside the planar sensor masks OCR responses of individual islets. Thus, we placed the PtTFPP/PDMS sensor into micron-sized wells surrounded by $\mathrm{O}_{2}$ impermeable epoxy. We improved the sensitivity by reducing the microwell width to less than the footprint of islets $(\sim 50 \mu \mathrm{m}$ in diameter), which highlights the importance of using microchannels to push the tissue against the sensor. We subsequently used PMMA to fabricate the channels (i.e., the top of the device) instead of more conventionally used and $\mathrm{O}_{2}$-permeable PDMS. Fabricating the device using air saturated PDMS abolished the sensor response during early trials consistent with $\mathrm{O}_{2}$ diffusion from the air saturated polymer swamping the sensor response.

Static OCR responses using our device were consistent with previous work once we normalized our data against individual islet volume [19]. We showed that islet OCR is highly uncoupled from ATP production using oligomycin consistent with other bulk islet studies (Fig. 4E) [30] [19]. A unique feature of our microsensors is that they are fabricated using a thin glass coverslip 
and are optically clear, both of which allow simultaneous imaging of responses. We used $10 \mu \mathrm{m}$ thick SU-8 photoresist for rapid prototyping in the present study. This diminished the optical throughput and image quality somewhat due to SU-8 having a slightly larger refractive index than glass ( 1.6 vs. 1.5) [34]. Future devices will be fabricated using a 3D glass printer to achieve optimal optics and thus improve dual color imaging [35]. We used this prototype to measure the OCR responses of individual islets while simultaneously imaging $\mathrm{Ca}^{2+}$-activity of the individual islet. Our microsensor shows high temporal resolution due to the digitization of the sensor. To dissect mechanisms of glycolysis and OxPhos, many labs use commercial instruments that are limited to a bulk measurement every 2-5 minutes, thereby masking islet dynamics, and prohibiting multiparametric imaging. Consequently, failing to reveal early timepoints that may reflect respiratory control by NADH substrate supply prior to ATP demand.

Loss of first phase insulin secretion is a hallmark of the early stages of T2D suggesting metabolic flux of the first phase response is central to the disease [3]. Therefore, the temporal dynamics provided by our device could lead to unique insight into the disease. We showed OxPhos is substrate-limited throughout first phase glucose-stimulated insulin secretion (Fig. 7). In low glucose (i.e., below the Km of Glucokinase), respiration was unchanged by 2DG and diminished by inhibiting mitochondrial pyruvate transport. These data suggest OxPhos in low glucose is $\mathrm{NADH}$ - rather than ADP-limited and set by a slow steady-state entry of pyruvate into mitochondria. Glucose stimulation resulted in a biphasic increase in respiration with the first response plateauing within $1 \mathrm{~min}$ of glucose-stimulation and a second steady rise in respiration initiated $\sim 28 \mathrm{~s}$ prior to $\mathrm{Ca}^{2+}$-influx (Fig. 7A). There was no obvious change in the OCR slope during or even shortly after $\mathrm{Ca}^{2+}$-influx suggesting no change in NADH supply and/or OxPhos. We postulate that the initial plateau is due to glycolytic NADH to supply OxPhos (Fig. 7A, lower left panel). If islets were in an ADP-limited state, we would expect glycolysis (which produces 2 net ATP / glucose) to decrease OxPhos. Furthermore, we postulate that the plateau represents maximal flux of glycolysis through 'inactive' PKM2. The subsequent linear rise in OCR is due to allosteric activation of PKM2 (Fig. 7B, lower right panel). This conclusion is based on TEPP-46-induced rise in basal OxPhos and the early linear rise in glucose-stimulated OCR that was fully separated from $\mathrm{Ca}^{2+}$ influx. PKM2 is heavily expressed in pancreatic islets [36] and tightly regulated by numerous posttranslational mechanisms including phosphorylation and acetylation [37] and by allosteric activation by FBP [32]. Thus, PKM2 is expected to transition from being inactive (i.e., low pyruvate flux) in low glucose to being active (i.e., high pyruvate flux) in high glucose [32]. The immediate glucose-stimulated dip in OCR in the presence of TEPP-46 could be due to pyruvate flux into mitochondria resulting in depolarization of mitochondrial membrane potential [38] and/or flux of pyruvate into mitochondrial metabolism through PC [39]. Reaching maximal glycolytic NADH is needed to offset this pyruvatestimulated dip in mitochondrial respiration. Alternatively, ATP produced by PKM2 could also decrease OxPhos as shown to regulate second phase secretion [14]; however, the speed of the dip is inconsistent with control by cytoplasmic ATP generation and our evidence suggests that NADH supply determines OxPhos just prior to stimulation. Consistent with a two-step glycolytic flux model, Patterson et al. previously showed a stepped rise in glucose-stimulated islet $\mathrm{NAD}(\mathrm{P}) \mathrm{H}$ response that due to the short time-lag between the steps $(<20 \mathrm{~s})$ suggested the stimulus was not triggered by $\mathrm{Ca}^{2+}$-influx but rather stimulated by entry of pyruvate into the 
TCA [18]. Overall, our data are consistent with a two-step response to glucose based on allosteric activation of PKM2 and a coincident increase in pyruvate flux into mitochondrial metabolism.

Two-step glycolytic models have been used to explain insulin secretion based on ADP-limited OxPhos [14] and $\mathrm{Ca}^{2+}$ stimulated mitochondrial NADH metabolism and OxPhos [40] [41]. In contrast, our model does not incorporate these mechanisms to explain first phase OxPhos. First, ADP-limited OxPhos is more relevant to second phase secretion. Second, we saw no evidence of $\mathrm{Ca}^{2+}$-induced OCR. This is perhaps not surprising since entry through the tightly regulated mitochondrial $\mathrm{Ca}^{2+}$ uniporter (MCU) would be delayed relative to cytoplasmic $\mathrm{Ca}^{2+}$-influx. This again suggests that mitochondrial $\mathrm{Ca}^{2+}$ activity would be more relevant in second phase insulin secretion [42]. Overall, our data show the importance of two-step glycolytic flux through PKM2 in first phase insulin secretion and highlights that not all mechanisms amplifying second phase insulin secretion are relevant to first phase secretion.

Our device opens the door to many more applications. First, we are interested in increasing the capability of multiparametric imaging with OCR. We used the optical clarity of the $\mathrm{O}_{2}$-sensor to image $\mathrm{Ca}^{2+}$ activity but could also easily work with other spectrally resolved sensors to simultaneously measure ATP, NADH, and glucose [43]. We are particularly interested in simultaneously imaging ATP using Perceval-HR to determine the extent to which ATP is coupled to OCR. Second, this device will allow us to explore respiratory heterogeneity of pancreatic islets. Beta-cells are genetically and functionally heterogeneous [44]; however, whether this impacts islet function is less clear. Preliminary evidence suggests some variability in glucose stimulated OxPhos in human and mice islets [19]. Our device offers the ability to explore this variability and further link it to $\mathrm{Ca}^{2+}$ activity. Third, our modular sensor design can be easily used with alternative islet-on-chip and with precision cut tissue slices [45]. We anticipate the $\mathrm{O}_{2}$-sensor will translate well to tissue slices if the tissue is pressed against the microwells. Finally, this device could be used clinically to assess tissue prior to transplantation. OCR has previously been shown to be a powerful predictor of insulin independence after transplantation [46]. This device could allow rapid screening of first phase OCR-response prior to islet transplantation for the treatment of type 1 diabetes [47]. Thus, we anticipate this study could inspire wide-ranging experimental and clinical applications.

In summary, our results show that pancreatic islets are in a substrate (NADH) limited state throughout first phase insulin secretion. We identified a role for PKM2 in controlling a biphasic glucose-stimulated OCR response. Activation of PKM2 further uncoupled the glucose-stimulated second rise from $\mathrm{Ca}^{2+}$-influx suggesting the glucose-stimulated OCR response requires glycolytic NADH and pyruvate entry prior to $\mathrm{Ca}^{2+}$-influx.

\section{ACKNOWLEDGMENTS}

R.R. was supported by an NSERC PGSD. This research was supported by grants from NSERC (RGPIN-2016-371705 and RTI-2018-00846) and CIHR (162330) to J.V.R. and stipend support to R.R. from NSERC (PGSD-535059-2019). 


\section{REFERENCES}

[1] T. Nilsson, V. Schultz, P.-O. Berggren, B. E. Corkey and K. Tornheim, "Temporal patterns of changes in ATP/ADP ratio, glucose 6-phosphate and cytoplasmic free $\mathrm{Ca} 2+$ in glucosestimulated pancreatic $\beta$-cells," Biochemical Journal, vol. 314, pp. 91-94, 1996.

[2] J.-C. Henquin, M. Nenquin, P. Stiernet and B. Ahren, "In Vivo and In Vitro GlucoseInduced Biphasic Insulin Secretion in the Mouse," Diabetes, vol. 55, no. 2, pp. 441-451, 2006.

[3] G. C. Weir and S. Bonner-Weir, "Reduced glucose-induced first-phase insulin release is a danger signal that predicts diabetes," The Journal of Clinial Investigation, vol. 131, no. 12, pp. 1-3, 2021.

[4] Z. Wang, T. Gurlo, A. V. Matveyenko, D. Elashoff, P. Wang, M. Rosenberger, J. A. Junge, R. C. Stevens, K. L. White, S. E. Fraser and P. C. Butler, "Live-cell imaging of glucoseinduced metabolic coupling of $\beta$ and $\alpha$ cell metabolism in health and type 2 diabetes," Communications Biology, vol. 4, no. 594, pp. 1-11, 2021.

[5] R. Bertrama, M. G. Pedersen, D. S. Lucianic and A. Sherman, "A simplified model for mitochondrial ATP production," Journal of Theoretical Biology, vol. 242, pp. 575-586, 2006.

[6] I. D. Dukes, M. S. McIntyre, R. J. Mertz, L. H. Philipson, M. W. Roe, B. Spencer and J. F. Worley, "Dependence on NADH Produced during Glycolysis for Beta-Cell Glucose Signaling," The Journal of Biological Chemistry, vol. 289, no. 15, pp. 10979-10982, 1994.

[7] K. Eto, Y. Tsubamoto, Y. Terauchi, T. Sugiyama, T. Kishimoto, N. Takahashi, N. Yamauchi, N. Kubota, S. Murayama, T. Aizawa, Y. Akanuma, S. Aizawa, H. Kasai, Y. Yazaki and T. Kadowaki, "Role of NADH shuttle system in glucose-induced activation of mitochondrial metabolism and insulin secretion," Science, vol. 283, no. 5404, pp. 981-5, 1999.

[8] D. Nakatsu, Y. Horiuchi, F. Kano, Y. Noguchi, T. Sugawara, I. Takamoto, N. Kubota, T. Kadowaki and M. Murata, "l-cysteine reversibly inhibits glucose-induced biphasic insulin secretion and ATP production by inactivating PKM2," PNAS, vol. Early Edition, pp. 1-10, 2015. 
[9] N. I. Mourad, M. Nenquin and J.-C. Henquin, "Metabolic amplifying pathway increases both phases of insulin secretion independently of Beta-cell actin microfilaments," American Journal of Physiology-Cell Physiology, vol. 299, no. 2, pp. C389-C398, 2010.

[10] J. C. Henquin, "Regulation of insulin secretion: a matter of phase control and amplitude modulation," Diabetologia, vol. 52, pp. 739-751, 2009.

[11] J. E. Campbell and C. B. Newgard, "Mechanisms controlling pancreatic islet cell function in insulin secretion," Nature Reviews Molecular Cell Biology, vol. 22, p. 142-158, 2021.

[12] A. I. Tarasov, F. Semplici, M. A. Ravier, E. A. Bellomo, T. J. Pullen, P. Gilon, I. Sekler, R. Rizzuto and G. A. Rutter, "The Mitochondrial Ca2+ Uniporter MCU Is Essential for Glucose-Induced ATP Increases in Pancreatic $\beta$-Cells," Plos One, vol. 7, no. 7, pp. 1-12, 2012.

[13] X. Quan, T. T. Nguyen, S.-K. Choi, S. Xu, R. Das, S.-K. Cha, N. Kim, J. Han, A. Wiederkehr, C. B. Wollheim and K.-S. Park, "Essential Role of Mitochondrial Ca2 Uniporter in the Generation of Mitochondrial pH Gradient and Metabolism-Secretion Coupling in Insulin-releasing Cells," The Journal of Biological Chemistry, vol. 290, no. 7, p. $4086-4096,2015$.

[14] S. L. Lewandowski, R. L. Cardone, H. R. Foster, T. Ho, E. Potapenko, C. P. H. R. VanDeusen, S. M. Sdao, T. C. Alves, X. Zhao, M. E. Capozzi, A. H. d. Souza, I. Jahan, C. J. Thomas and C. S. N, "Pyruvate kinase controls signal strength in the insulin secretory pathway," Cell Metabolism, vol. 32, no. 5, pp. 735-750, 2020.

[15] H. I. C. B. C. B. Peter A.Antinozzi, "Mitochondrial Metabolism Sets the Maximal Limit of Fuel-stimulated Insulin Secretion in a Model Pancreatic Beta Cell: A SURVEY OF FOUR FUEL SECRETAGOGUES," JBC, 2002.

[16] E. Haythorne, M. Rohm, M. v. d. Bunt, M. F. Brereton, A. I. Tarasov, T. S. Blacker, G. Sachse, R. T. Exposito, S. Davis, O. Baba, R. Fischer, M. R. Duchen, P. Rorsman, J. I. MacRae and F. M. A, "Diabetes causes marked inhibition of mitochondrial metabolism in pancreatic $\beta$-cells," Nature Communications, vol. 10, no. 2474, pp. 1-17, 2019.

[17] Y. H. J. O. V. e. a. Will, "Analysis of mitochondrial function using phosphorescent oxygensensitive probes," Nat Protoc, 2006.

[18] G. H. Patterson, S. M. Knobel, P. Arkhammar, O. Thastrup and D. W. Piston, "Separation of the glucose-stimulated cytoplasmic and mitochondrial NAD $(\mathrm{P}) \mathrm{H}$ responses in pancreatic islet beta cells," PNAS, vol. 97, no. 10, p. 5203-5207, 2000.

[19] E. P. Taddeo, L. Stiles, S. Sereda, E. Ritou, D. M. Wolf, M. Abdullah, Z. Swanson, J. Wilhelm, M. Bellin, P. McDonald, K. Caradonna, A. Neilson, M. Liesa and O. S. Shirihai, "Individual islet respirometry reveals functional diversity within the islet population of mice 
and human donors," Molecular Metabolism, vol. 16, pp. 150-159, 2018.

[20] A. Nászai, E. Terhes, J. Kaszaki, M. Boros and L. Juhász, "Ca(2+)N It Be Measured? Detection of Extramitochondrial Calcium Movement With High-Resolution FluoRespirometry," Scientific Reports, vol. 9, no. 19229, pp. 1-13, 2019.

[21] K. S. Sankar, B. J. Green, A. R. Crocker, J. E. Verity, S. M. Altamentova and J. V. Rocheleau, "Culturing Pancreatic Islets in Microfluidic Flow Enhances Morphology of the Associated Endothelial Cells," PLoS One, vol. 6, no. 9, pp. 1-9, 2011.

[22] P. N. Silva, B. J. Green, S. M. Altamentovab and J. V. Rocheleau, "A microfluidic device designed to induce media flow throughout pancreatic islets while limiting shear-induced damage," Lab on a Chip, vol. 13, no. 4374, p. 4374-4384, 2013.

[23] P. N. Silva, Z. Atto, R. Regeenes, U. Tufa, Y. Y. Chen, W. C. W. Chan, A. Volchuk, D. M. Kilkenny and J. V. Rocheleau, "Highly efficient adenoviral transduction of pancreatic islets using a microfluidic device," Lab on a Chip, vol. 16, no. 15, pp. 2921-2934, 2016.

[24] P. C. Thomas, M. Halter, A. Tona, S. R. Raghavan, A. L. Plant and S. P. Forry, "A Noninvasive Thin Film Sensor for Monitoring Oxygen Tension during in Vitro Cell Culture," Analytical Chemistry, vol. 81, no. 22, p. 9239-9246, 2009.

[25] P. Buchwald, "FEM-based oxygen consumption and cell viability models for avascular pancreatic islets," Theoretical Biology and Medical Modelling, vol. 6, no. 5, pp. 1-13, 2009.

[26] A. D. Edelstein, M. A. Tsuchida, N. Amodaj, H. Pinkard, R. D. Vale and N. Stuurman, "Advanced methods of microscope control using $\mu$ Manager software," Journal of Biological Methods, vol. 1(2), pp. 1-10, 2014.

[27] J. E. Paz-Miguel, R. Flores, P. Sánchez-Velasco, G. Ocejo-Vinyals, J. E. d. Diego, J. L. d. Rego and F. Leyva-Cobián, "Reactive Oxygen Intermediates During Programmed Cell Death Induced in the Thymus of the Ts(1716)65Dn Mouse, a Murine Model for Human Down's Syndrome," The Journal of Immunology, vol. 163, no. 10, pp. 5399-5410, 1999.

[28] J. M. Vanderkooi, G. Maniara, T. J. Green and D. F. Wilson, "An Optical Method for Measurement of Dioxygen Concentration Based upon Quenching of Phosphorescen," The Journal of Biological Chemistry, vol. 262, no. 12, pp. 5476-5482, 1987.

[29] Y. Mao, Y. Gao, S. Wu, S. Wua, J. Shi, B. Zhou and Y. Tian, "Highly enhanced sensitivity of optical oxygen sensors using microstructured PtTFPP/PDMS-pillar arrays sensing layer," Sensors and Actuators B: Chemical, vol. 251, pp. 495-502, 2017.

[30] J. D. Wikstrom, S. B. Sereda, L. Stiles, A. Elorza, E. M. Allister, A. Neilson, D. A. Ferrick, M. B. Wheeler and O. S. Shirihai, "A Novel High-Throughput Assay for Islet Respiration Reveals Uncoupling of Rodent and Human Islets," Plos One, vol. 7, no. 5, pp. 1-7, 2012. 
[31] S.-K. Jung, L. M. Kauri, W.-J. Qian and R. T. Kennedy, "Correlated Oscillations in Glucose Consumption, Oxygen Consumption, and Intracellular Free Ca2+ in Single Islets of Langerhans," Journal of Biological Chemistry, vol. 275, no. 9, pp. 6642-3320, 2000.

[32] K. Ashizawa, M. C. Willingham, C.-M. Liangs and S.-y. Cheng, "In Vivo Regulation of Monomer-Tetramer Conversion of Pyruvate Kinase Subtype M2 by Glucose Is Mediated via Fructose 1,6-Bisphosphate," The Journal of Biological Chemistry, vol. 266, no. 25, pp. 16842-16846, 1991.

[33] S.-K. Lee and I. Okura, "Photostable Optical Oxygen Sensing Material: Platinum Tetrakis(pentafluorophenyl)porphyrin Immobilized in Polystyrene," Analytical Communications, vol. 34, pp. 185-188, 1994.

[34] S. Ashraf, I. Niskanen, B. Kanyathare, E. Vartiainen, C. Mattsson, R. Keikkila and G. Thungstrom, "Determination of complex refractive index of SU-8 by Kramers-Kronig dispersion relation method at the wavelength range 2.5-22.0 $\square$ um," Journal of Quantitative Spectroscopy and Radiative Transfer, vol. 224, pp. 309-311, 2019.

[35] N. Burshtein, S. ToChan, K. Toda-Peters, A. Q. Shen and S. J. Haward, "3D-printed glass microfluidics for fluid dynamics and rheology," Current Opinion in Colloid \& Interface Science, vol. 43, pp. 1-14, 2019.

[36] G. A. Martens, L. Jiang, K. Verhaeghen, J. B. Connolly, S. G. Geromanos, G. Stangé, L. V. Oudenhove, B. Devreese, K. H. Hellemans, Z. Ling, C. V. Schravendijk, D. G. Pipeleers and J. P. C. Vissers, "Protein Markers for Insulin-Producing Beta Cells with Higher Glucose Sensitivity," Plos One, vol. 5, no. 12, pp. 1-13, 2010.

[37] G. Prakasam, M. A. Iqbal, R. N. K. Bamezai and S. Mazurek, "Posttranslational Modifications of Pyruvate Kinase M2: Tweaks that Benefit Cancer," Frontiers in Oncology, vol. 8, pp. 1-12, 2018.

[38] P. B. d. Andrade, M. Casimir and P. Maechler, "Mitochondrial activation and the pyruvate paradox in a human cell line," FEBS Letters, vol. 578, no. 3, pp. 224-228, 2004.

[39] J. V. Rocheleau, W. S. Head, W. E. Nicholson, A. C. Powers and D. W. Piston, "Pancreatic Islet $\beta$-Cells Transiently Metabolize Pyruvate," Journal of Biological Chemistry, vol. 277, no. 34, p. 30914-30920, 2002.

[40] A. Wiederkehr, G. Szanda, D. Akhmedov, C. Matak, C. W. Heizmann, K. Schoonjans, T. Pozzan, A. Spat and C. B. Wollheim, "Mitochondrial Matrix Calcium Is an Activating Signal for Hormone Secretion," Cell Metabolism, vol. 13, no. 5, pp. 601-11, 2011.

[41] a. R. Sweet and M. Gilbert, "Contribution of Calcium Influx in Mediating GlucoseStimulated Oxygen Consumption in Pancreatic Islets," Diabetes, vol. 55, no. 12, pp. 35093519, 2006. 
[42] S. Marchi and P. Pinton, "The mitochondrial calcium uniporter complex: molecular components, structure and physiopathological implications," The Journal of Physiology, vol. 592, no. 5, p. 829-839, 2013.

[43] L. Sanford and A. Palmer, "Recent Advances in Development of Genetically Encoded Fluorescent Sensors," Methods Enzymology, vol. 589, pp. 1-49, 2017.

[44] G. D. Gutierrez, J. Gromada and L. Sussel, "Heterogeneity of the Pancreatic Beta Cell," Frontiers in Genetics, vol. 8, pp. 1-9, 2017.

[45] N. Rafiei, A. Au, M. G. Moghadam, R. Regeenes, Y. Wang, C. M. Yip, H. Gaisano and J. V. Rocheleau, "Design of a Versatile Microfluidic Device for Imaging Precision-Cut-Tissue Slices," bioRxiv, pp. 1-19, 2022.

[46] K. K. Papas, M. D. Bellin, D. E. R. Sutherland, T. M. Suszynski, J. P. Kitzmann, E. S. Avgoustiniatos and A. C. Gruessner, "Islet Oxygen Consumption Rate (OCR) Dose Predicts Insulin Independence in Clinical Islet Autotransplantation," Plos One, vol. 10, no. 8, pp. 1$11,2015$.

[47] A. M. J. Shapiro, C. Ricordi, B. J. Herin, H. Auchincloss, R. Lindblad, R. P. Robertson, A. Secchi, M. D. Brendel, T. Berney, D. C. Brennan, E. Cagliero, R. Alejandro, E. A. Ryan and B. DiMercurio, "International trial of the Edmonton protocol for islet transplantation," The New England Journal of Medicine, vol. 355, pp. 1318-1330, 2006. 


\section{Figure Captions}

\section{Figure 1}

COMSOL simulations reveal greater sensitivity when patterning $\mathrm{O}_{2}$ sensor in microwells.

A) A schematic of various entry points for external $\mathrm{O}_{2}$ into the microfluidic device. The planar sensor made from PDMS allows $\mathrm{O}_{2}$ from the environment to enter and leave lowering sensor sensitivity directly beneath the islet. Black arrows indicate regions where $\mathrm{O}_{2}$ can enter and leave.

B) $\mathrm{O}_{2}$ transport in the device in the absence (left) and presence (right) of an $\mathrm{O}_{2}$ consuming islet with the PtTFPP/PDMS in a uniform plane underneath. White dotted line represents distance across islet $(\mu \mathrm{m})$.

C) Simulated $\mathrm{O}_{2}$ concentrations across the PtTFPP/PDMS in the presence and absence of an islet reveal very small response across the planar sensor.

D) A schematic with $\mathrm{O}_{2}$ entry points sealed by patterning SU-8. This arrangement helps digitize the sensor readout and prevent $\mathrm{O}_{2}$ from travelling between wells.

E) $\mathrm{O}_{2}$ concentration distributions in 10 (right), 50 (middle) and 100 (left) $\mu$ m wells with an islet above. $10 \mu \mathrm{m}$ sized wells show greater sensitivity to $\mathrm{O}_{2}$ compared to 50 and $100 \mu \mathrm{m}$ sized well designs.

F) Simulated $\mathrm{O}_{2}$ concentrations in 10,50 and $100 \mu \mathrm{m}$ wells underneath the islet reveal a dramatic increase in sensitivity with $10 \mu \mathrm{m}$ wells.

G) $\mathrm{O}_{2}$ concentration distributions in 10 (bottom), 30 (middle) and 60 (top) $\mu$ m height wells reveal no changes in sensor response.

H) Simulated $\mathrm{O}_{2}$ concentrations in 10,30 and $60 \mu \mathrm{m}$ height wells reveal no change in OCR sensitivity (right).

\section{Figure 2}

Determining the impact of flow rate and islet proximity on $\mathrm{O}_{2}$ sensitivity.

A) Varying flow rates have minimal effect on $\mathrm{O}_{2}$ levels.

B) Islet proximity is measured as distance between the bottom of the islet to the top of the microwell plane.

C) Simulated $\mathrm{O}_{2}$ concentrations reveal proximity to enhance microwell sensitivity. 
D) Glucose-stimulated $\mathrm{O}_{2}$ concentrations in the wells when islets are subjected to 2- and 20-mM glucose reveal greater OCR in the center of the islet.

E) Simulated $\mathrm{O}_{2}$ concentrations when islets are subjected to 2- and 20-mM glucose show a large response to an increase in OCR at $20 \mathrm{mM}$ glucose.

\section{Figure 3}

Characterization of the $\mathrm{O}_{2}$ sensor.

A) $\mathrm{O}_{2}$ sensitive microwells in the presence of $\mathrm{ddH}_{2} \mathrm{O}$ (left) and $10 \%$ sodium sulfite (right). Scale bare represents $10 \mu \mathrm{m}$.

B) The relationship between $\mathrm{O}_{2}$ concentration and normalized fluorescence modelled using the Stern-Volmer relationship. A representative two-point calibration curve to calculate changes in $\mathrm{O}_{2}$. Data in figure are means $\pm \mathrm{SD}$ for 10 independent repeats.

C) A temporal trace of switching from a $0 \%$ to $100 \%$ air saturated solution revealing a $t_{95}$ of 12.4 $\pm 0.69 \mathrm{~s}$ for 6 independent repeats. Red dotted lines represent $t_{95}$ interval.

D) A temporal trace of switching from a $100 \%$ to $0 \%$ air saturated solution revealing a $t_{95}$ of 4.24 $\pm 0.18 \mathrm{~s}$ for 6 independent repeats. Red dotted lines represent $t_{95}$ interval.

Data in figure are means \pm SEM unless otherwise stated.

\section{Figure 4}

An on-chip $\mathrm{O}_{2}$ sensor to measure OCR in individual pancreatic islets.

A) Representative widefield fluorescence images of $\mathrm{O}_{2}$ sensitive microwells underneath islet while flowing the indicated respiratory inhibitors. Scale bars represent $10 \mu \mathrm{m}$.

B) Representative widefield white light images of different sized islets trapped in device. Scale bars represent $10 \mu \mathrm{m}$.

C) Basal OCR of individual mouse islets relative to islet volume.

D) Averaged OCR traces of mouse islets exposed to $20 \mathrm{mM}$ glucose, $5 \mu \mathrm{M}$ oligomycin, $2 \mu \mathrm{M}$ FCCP and $5 \mu \mathrm{M}$ rotenone/antimycin A.

E) Islet bioenergetic measurements extracted from the respiratory inhibitor treatments. Glucose stimulated OCR, proton leak and maximal respiration relative to basal OCR.

Data in figure are means \pm SEM. $* * * *$ indicates $\mathrm{p} \leq 0.0001$ and $* * *$ indicates $\mathrm{p} \leq 0.001$ by oneway ANOVA. $\mathrm{N}=14$ islets. 


\section{Figure 5}

Dual-colour imaging of OCR and $\mathrm{Ca}^{2+}$ in individual islets reveals a two-step increases in OCR response.

A) Representative images of a Cal-520 stained mouse islet and $\mathrm{O}_{2}$ sensitive microwells underneath the islet after stimulating with 2- (left) and 20-mM glucose (right) show a visible increase in fluorescence in both sensors. Scale bars represent $10 \mu \mathrm{m}$.

B) A representative OCR and $\mathrm{Ca}^{2+}$ traces of an individual mouse islet show OCR to precede $\mathrm{Ca}^{2+}$ influx. The black arrow indicates treatment change from 2- to $20-\mathrm{mM}$ glucose. The $\mathrm{Ca}^{2+}$ response was normalized to the Cal-520 fluorescence intensity during low glucose treatment.

C-D) Averaged area under the curve (AUC) of $\mathrm{Ca}^{2+}(\mathrm{C})$ and OCR (D) traces during low glucose treatment, phase 0 and $1 \mathrm{Ca}^{2+}$ responses. Analyzed areas are indicated by the blue, red and green lines in B).

E-F) Average normalized changes in OCR determined by setting "time $=0$ min" based on the start of $20 \mathrm{mM}$ glucose stimulation (E) and the beginning of phase $1 \mathrm{Ca}^{2+}$ response $(\mathrm{F})$. Changes in OCR were normalized to the six time points prior to $t=0 \mathrm{~min}$. Cyan line in F) indicates the fitting for the start of the second OCR rise.

G) Averaged slopes of the two-step OCR responses to high glucose stimulation.

Data in figure are means \pm SEM. $* * * *$ indicates $\mathrm{p} \leq 0.0001$ and $* * *$ indicates $\mathrm{p} \leq 0.001$ by oneway ANOVA. $\mathrm{N}=7$ islets.

\section{Figure 6}

Glycolytic flux and pyruvate entry into mitochondria control OCR.

A) Simplified metabolic model depicting the impact of glycolysis derived NADH and PKM2 activity on OCR. NADH from glycolysis is shuttled into the mitochondria for charging the electron transport chain. PKM2 controls pyruvate flux into the mitochondria for tricarboxylic acid (TCA cycle) metabolism which also generates NADH to further fuel the electron transport chain. The substrate (NADH) supply establishes the proton gradient stimulating OCR and ATP production. In excess substrate supply, OCR will be inhibited by a rise in the ATP/ADP ratio.

B) Normalized basal OCR rates in the presence of 2DG, a glycolysis inhibitor, and UK5099, a mitochondrial pyruvate carrier inhibitor and $20 \mathrm{mM}$ glucose. Significant changes relative to 2 $\mathrm{mM}$ glucose are seen with UK5099 and $20 \mathrm{mM}$ glucose treatment.

C) Normalized changes in OCR of islets in $20 \mathrm{mM}$ glucose in response to $20 \mathrm{mM}+2 \mathrm{DG}$ reveals substrate supply is needed to stimulate OCR.

D) Averaged OCR from 3-minute intervals during steady state of each treatment reveals 2DG to significantly decrease OCR back down to basal levels in the presence of $20 \mathrm{mM}$ glucose. 
E) Preincubating islets with PKM2 activator (4 $\mu \mathrm{M}$ TEPP-46) shows a significant increase in basal OCR levels consistent with greater pyruvate flux.

F) Islets preincubated in $4 \mu \mathrm{M}$ TEPP-46 respond to $20 \mathrm{mM}$ glucose with a rapid drop in OCR followed by a linear increase in OCR.

G) A representative OCR and $\mathrm{Ca}^{2+}$ trace of an individual islet TEPP-46 treated shows OCR precedes $\mathrm{Ca}^{2+}$-influx.

H) Individual islet traces were normalized to the onset of $20 \mathrm{mM}$ glucose stimulation to reveal a rapid drop followed by linear increase in OCR prior to $\mathrm{Ca}^{2+}$-influx.

Data in figure are means \pm SEM. $* * *$ indicates $\mathrm{p} \leq 0.001$, ** indicates $\mathrm{p} \leq 0.01$, and $*$ indicates $\mathrm{p}$ $\leq 0.05$ by one-way ANOVA. $\mathrm{N}=5-12$ islets.

\section{Figure 7}

A model depicting the biphasic behavior of OCR during first phase insulin secretion.

A) Upon glucose stimulation, glycolytic NADH is shuttled into the mitochondria for OxPhos, stimulating the first rise in OCR. A plateau in the OCR response follows shortly due to inactivated PKM2 (in dimer form).

B) As glycolytic metabolism continues, the accumulation of upstream glycolytic metabolite, FBP, allosterically activates PKM2 (dimer to tetramer transition) causing a large pyruvate flux into the mitochondria. This pyruvate entry further stimulates TCA cycle metabolism to generate more NADH for OxPhos stimulating the second rise in OCR. 
IsletbioRxiv preprint doi: https://doi.org/10.1101/2022.03.02.482671; this version posted March 3, 2022. The copyright holder for this preprint s (Wthich was not certified by peer review) is the author/funder, who hag granted bioRxiv a license to display the preprint in perpetuity. It is made PMMA available under aCC-BY-NC-ND 4.0 International license.

SU-8 (Epoxy based Photoresist)

PtTFPP/PDMS

Glass Slide

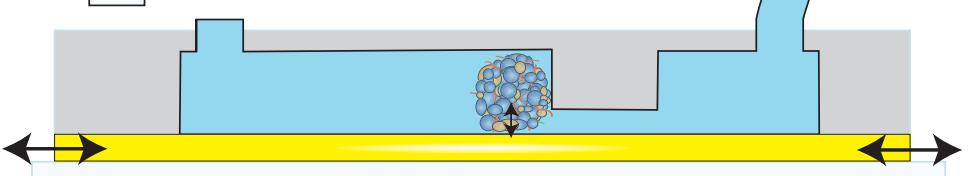

B
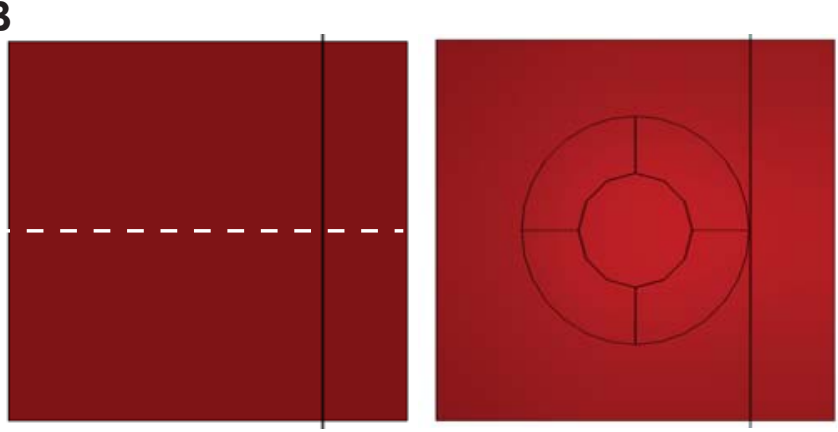

$21 \%$

D

E

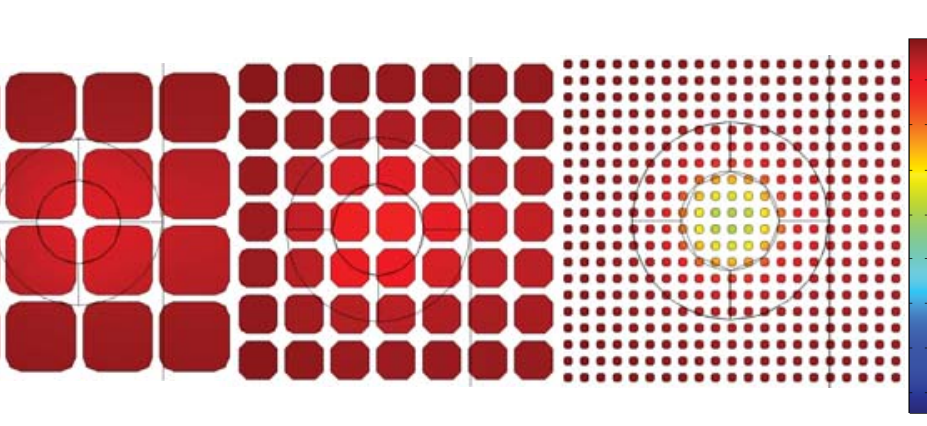

G
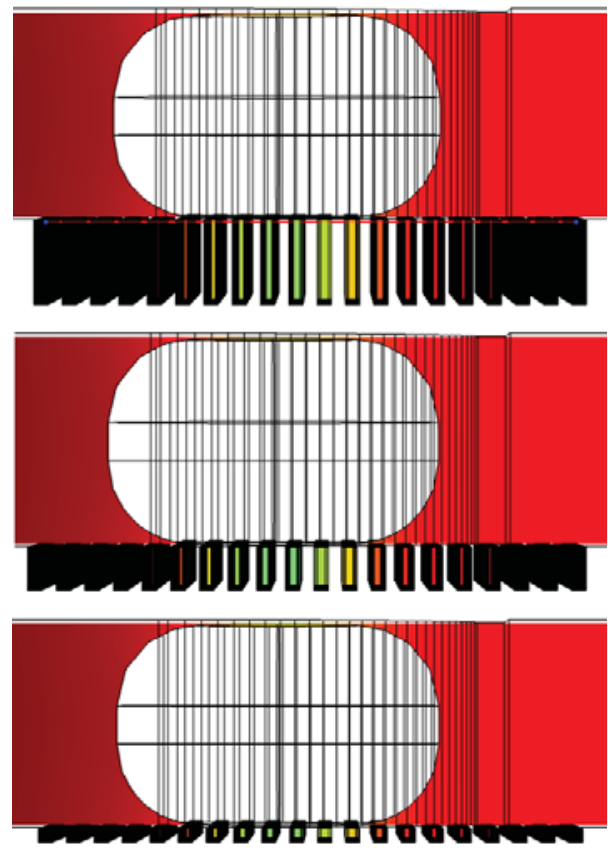

$15 \%$

$\mathbf{F}$

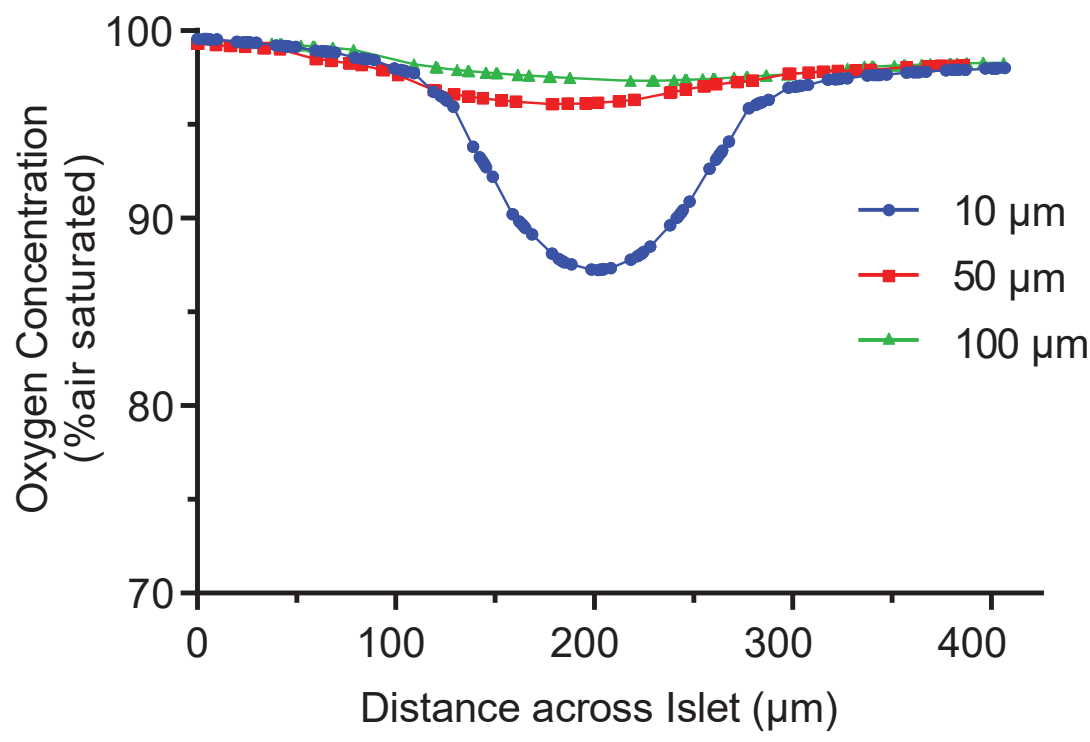

H

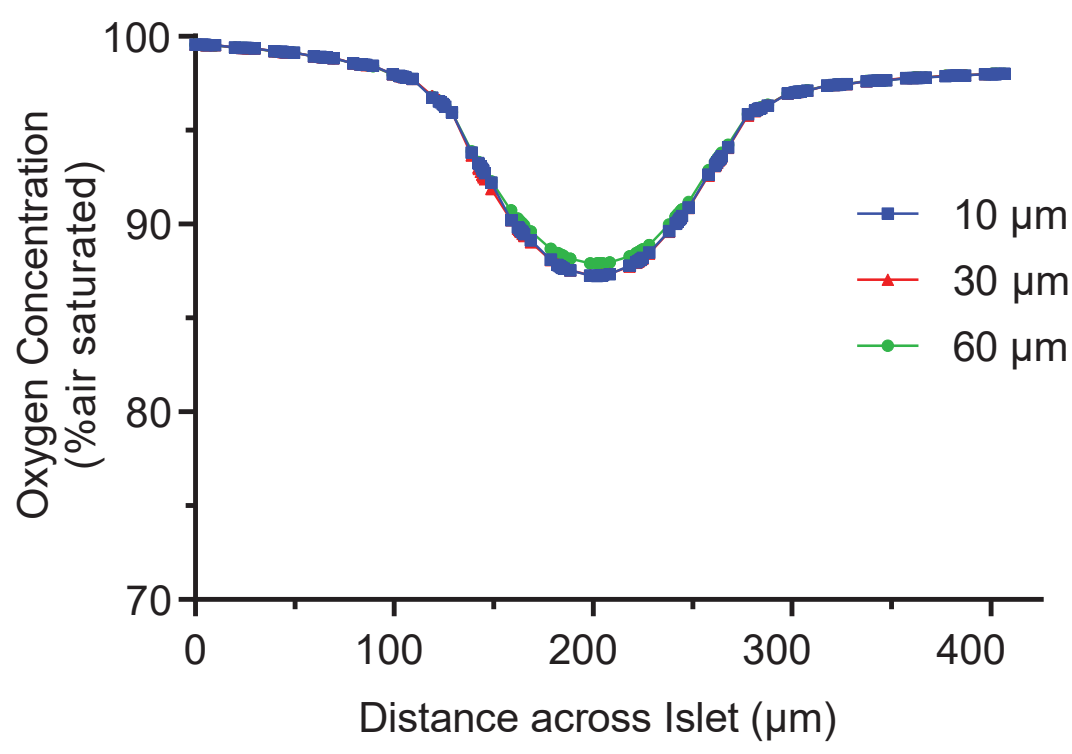

Fig 1 
bioRxiv preprint doi: https://doi.org/10.1101/2022.03.02.482671; this version posted March 3, 2022. The copyright holder for this preprint

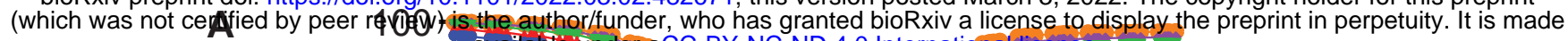

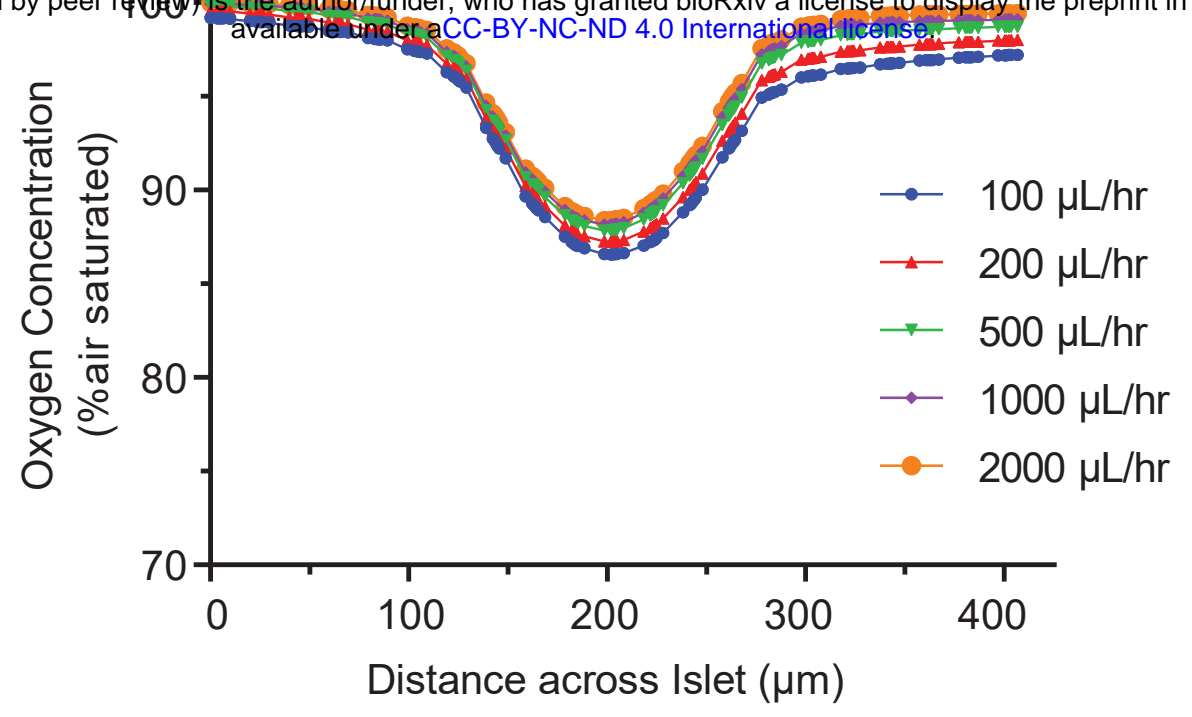

B

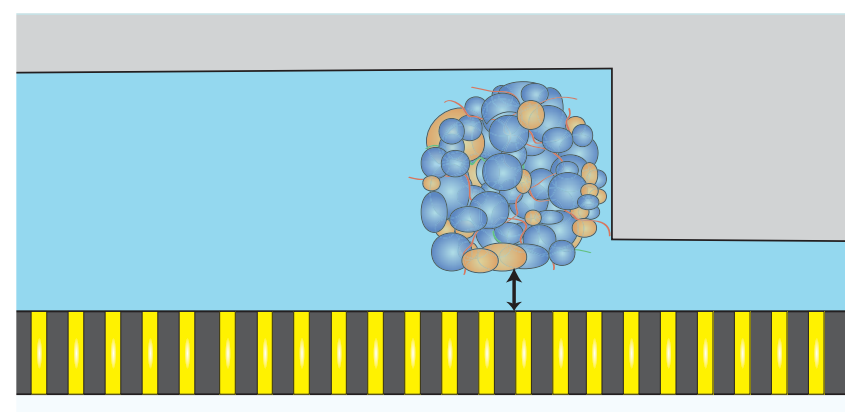

D

\section{$2 \mathrm{mM}$}

$20 \mathrm{mM}$

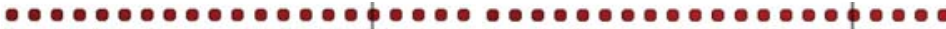
$\circ$

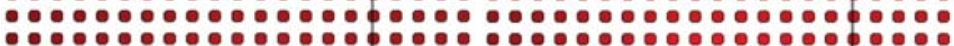
$\bullet \bullet \bullet \bullet \bullet \bullet \bullet \bullet \bullet \bullet \bullet \bullet \bullet \bullet \bullet \bullet \bullet \bullet \bullet \bullet \bullet \bullet \bullet \bullet \bullet \bullet \bullet \bullet \bullet \bullet \bullet \bullet \bullet 申 \bullet \bullet \bullet \bullet$

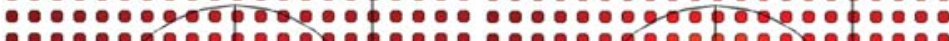

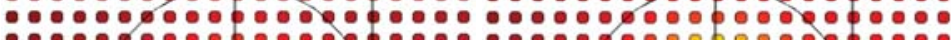

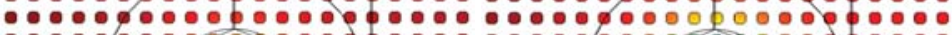

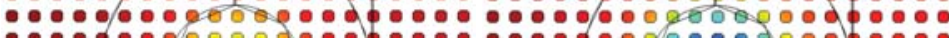

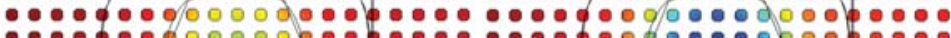

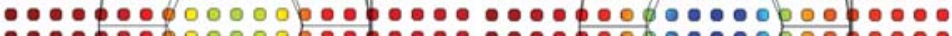

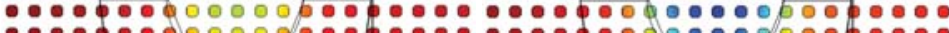

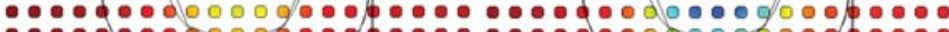

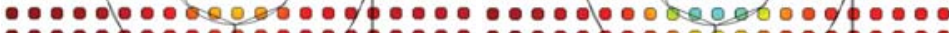
$\because \bullet \bullet \bullet$ : - : : : : : : : : :
C

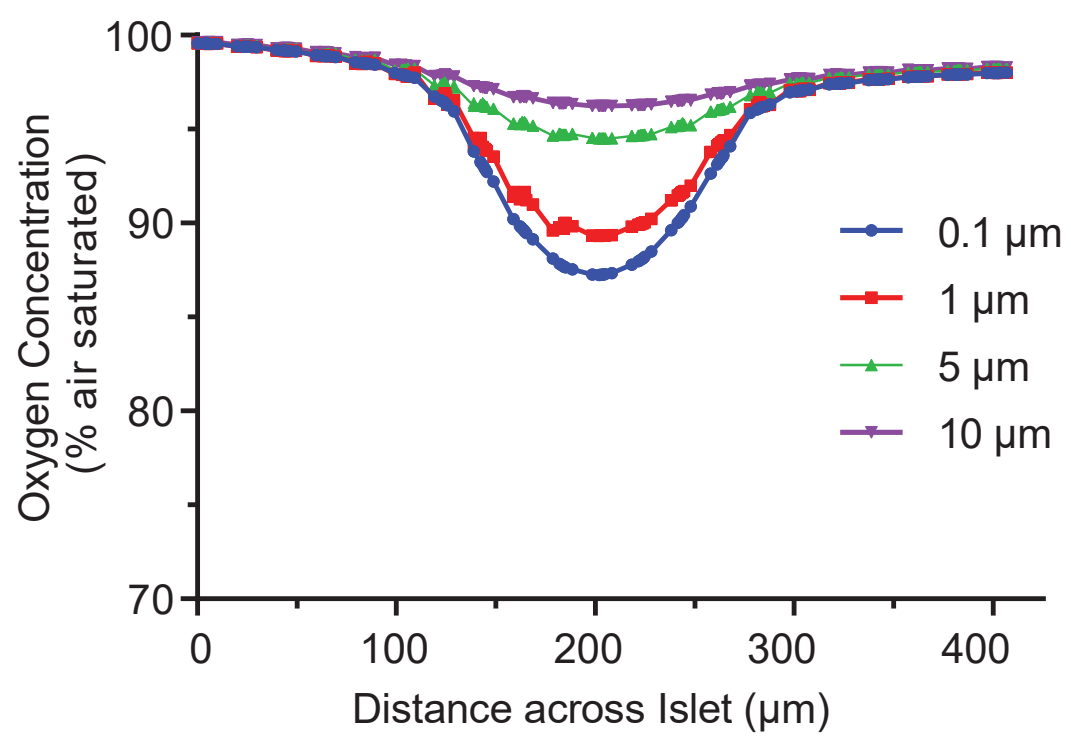

E

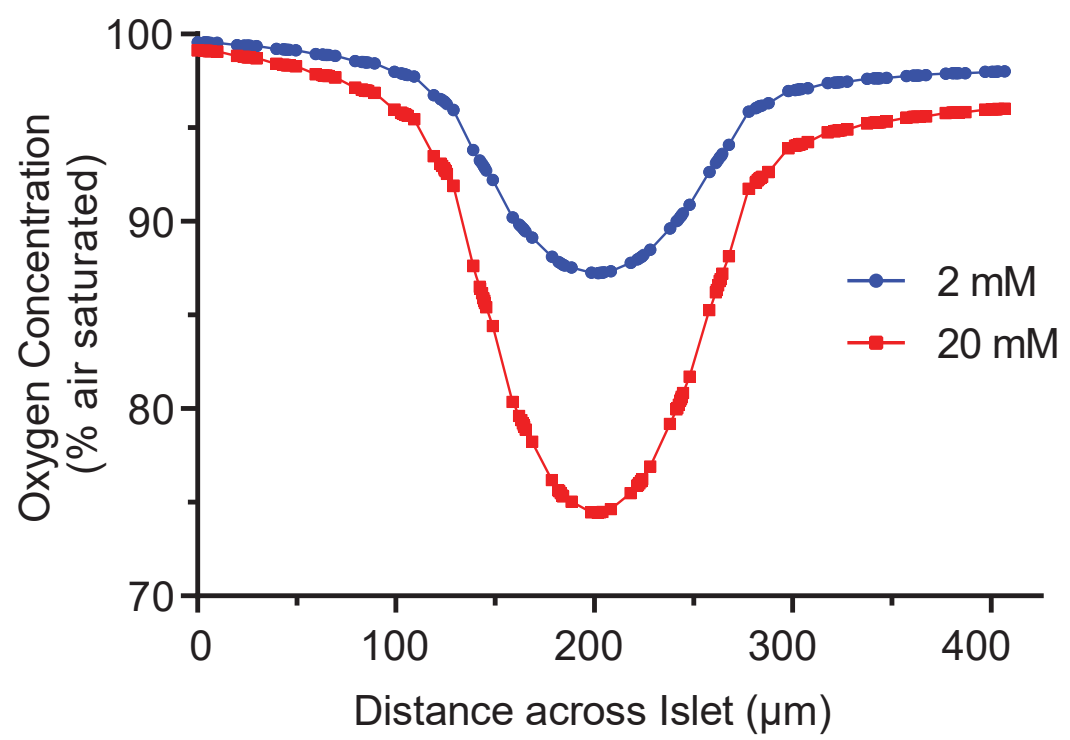

\section{Fig 2}


bioRxiv preprint doi: https://doi.org/10.1101/2022.03.02.48267d-athisqersion posted March 3, 2022. The copyright holder for this preprint

A (which was not certified by peer review) is the author/funder, who has granted bio Rxiv a license to display the preprint in perpetuity. It is made available under aCC-BY-NC-ND 4.0 International license.

B

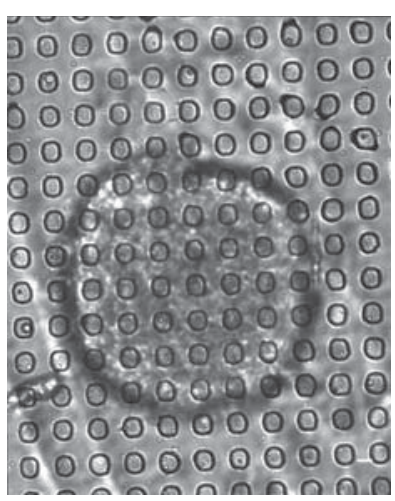

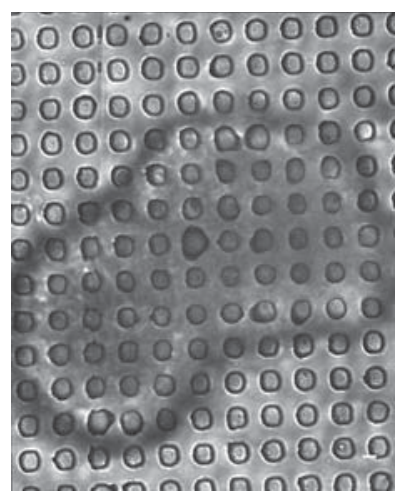

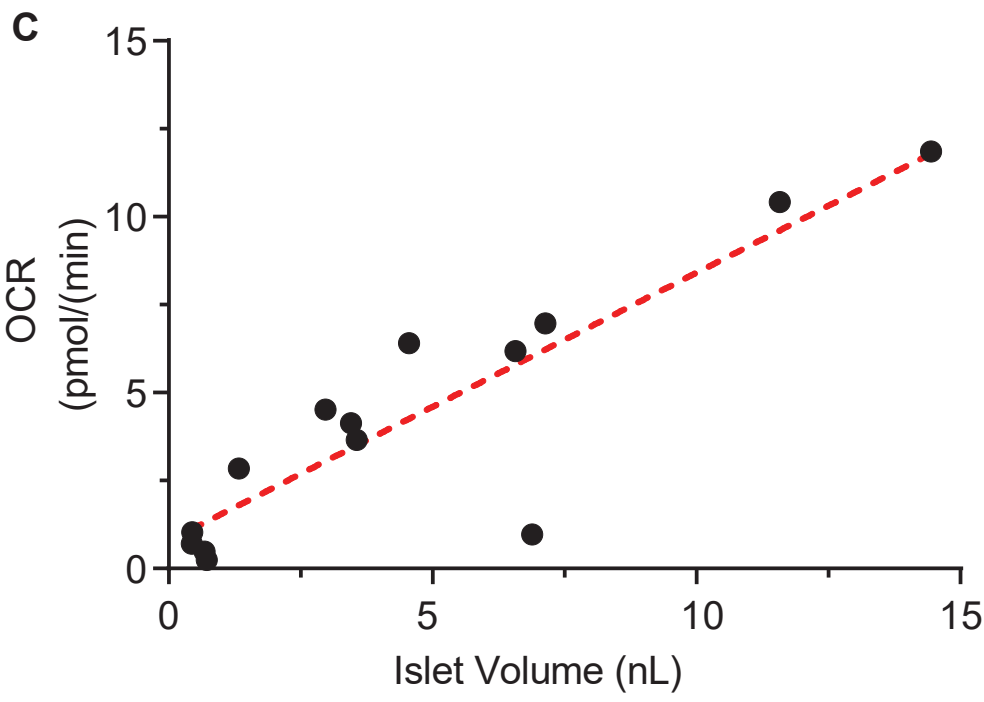

E

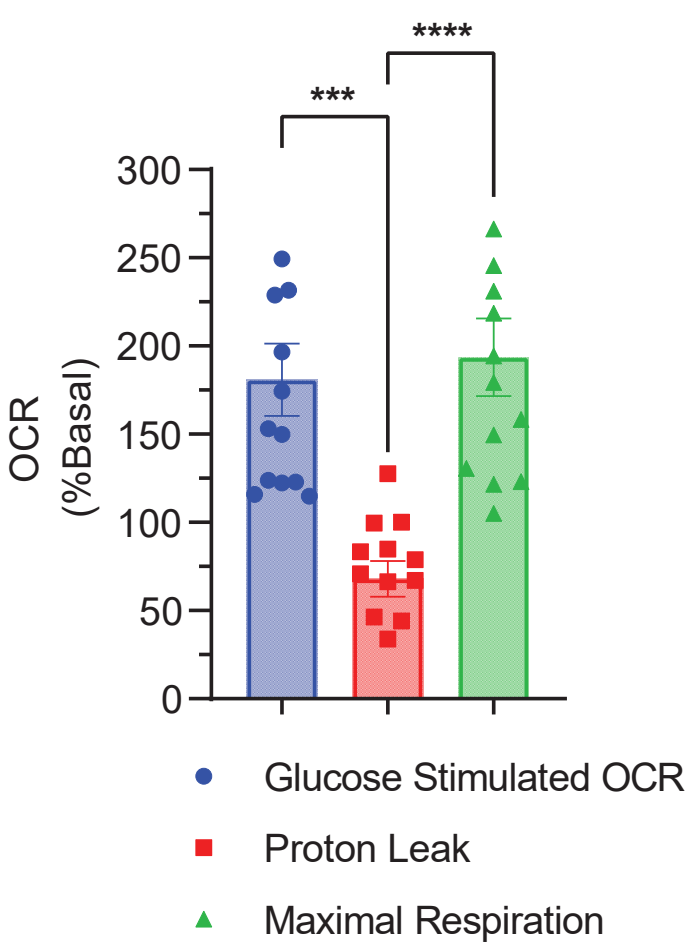


bioRxiv preprint doi: https://doi.org/10.1101/2022.03.02.482671; this version posted March 3, 2022. The copyright holder for this preprint

A

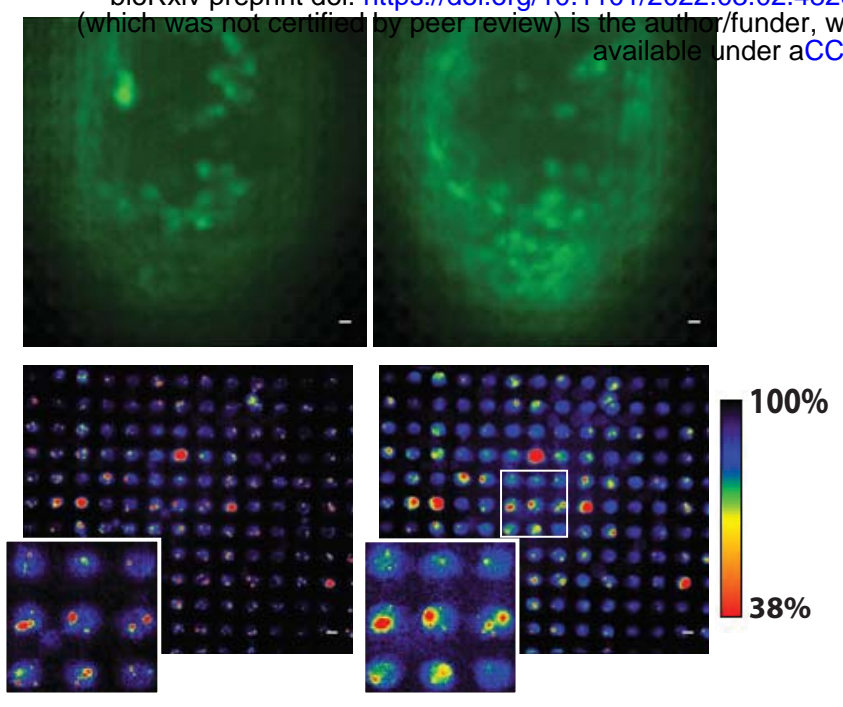

C

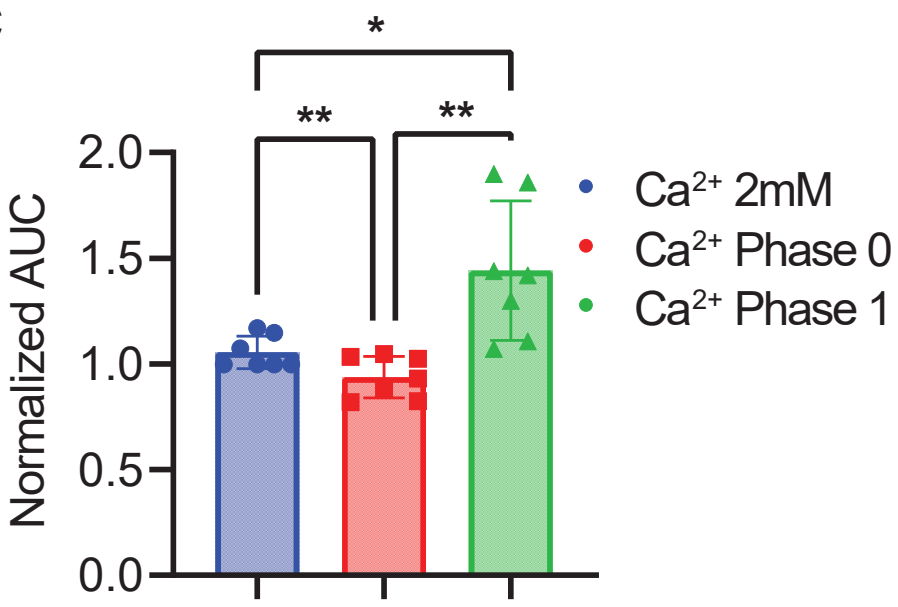

D

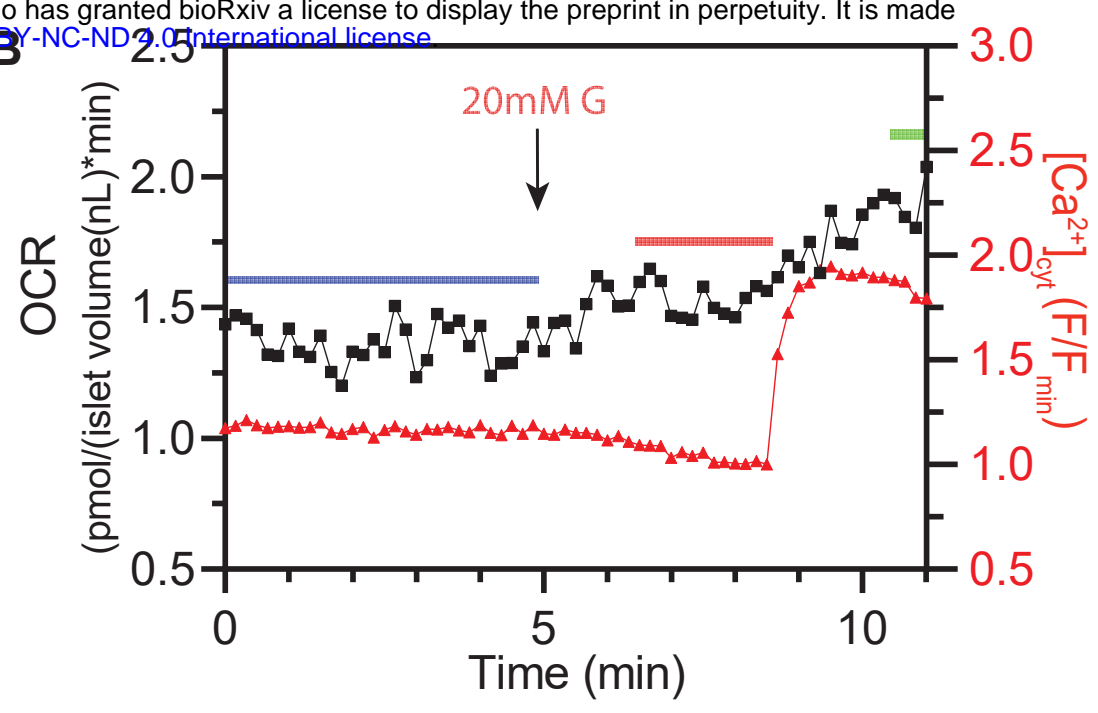

E

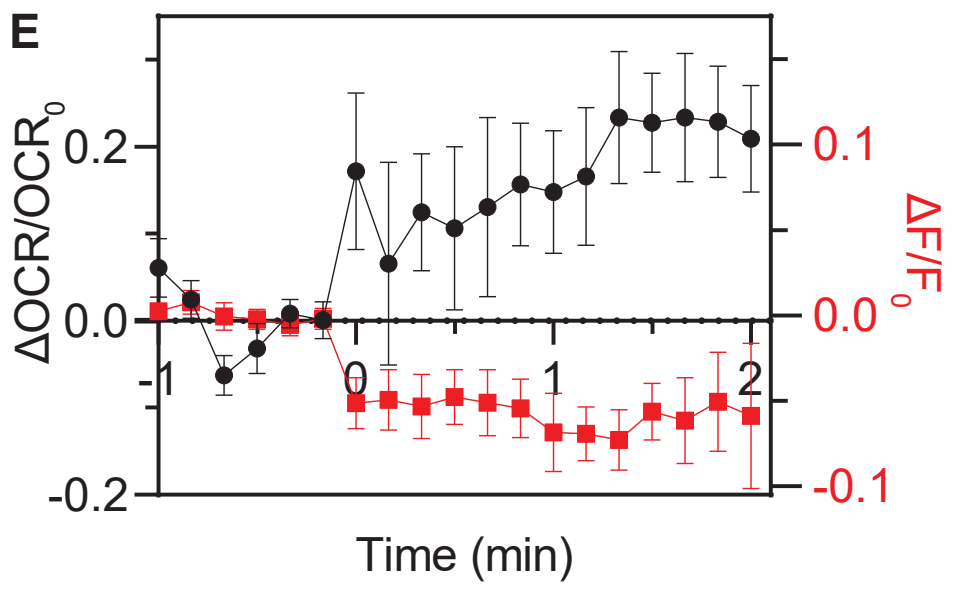

F
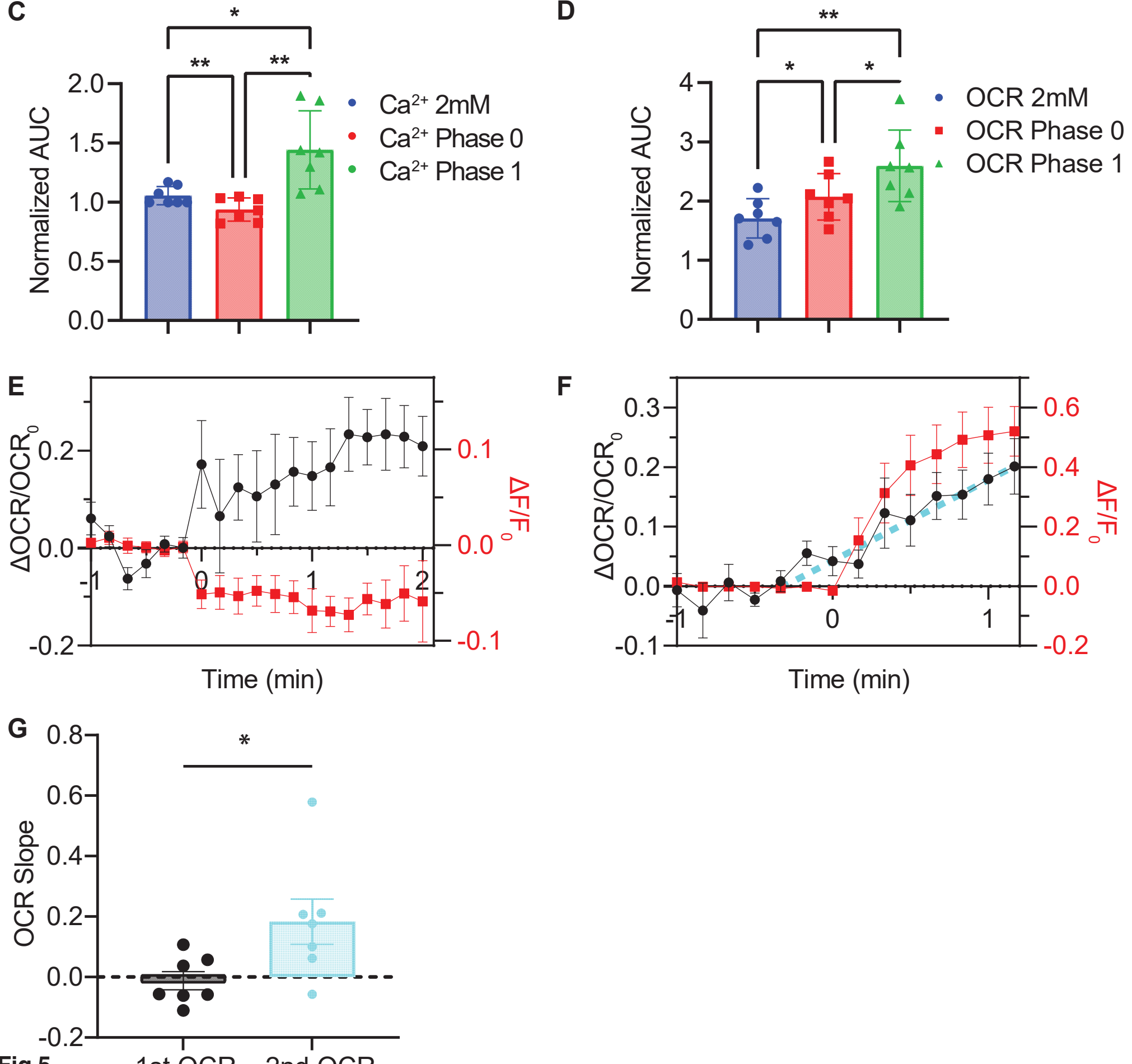

Fig 5

1st OCR 2nd OCR 
bioRxiv preprint doi: https://doi.org/10.1101/2022.03.02.482671; this version posted March 3, 2022. The copyright holder for this preprint (which was not certified by peer review) is the author/funder, who has granted bioRxiv a license to display the preprint in perpetuity. It is made available under aCC-BY-NC-ND 4.0 International license.

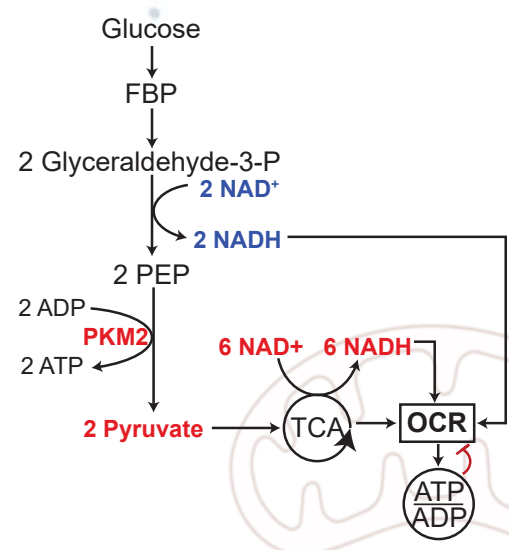

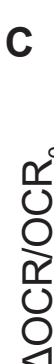
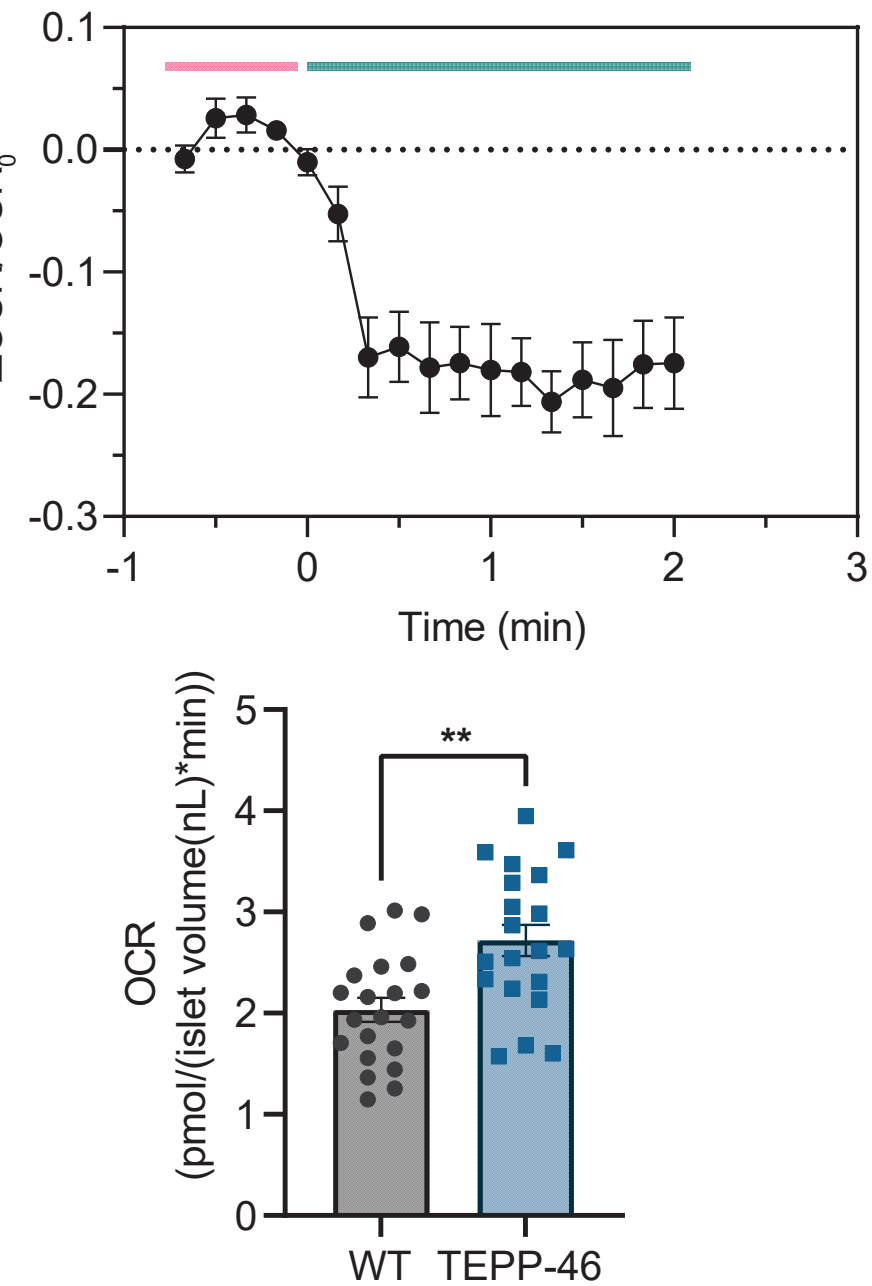

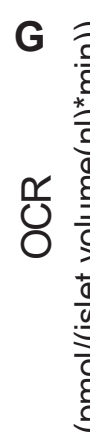

Fig 6
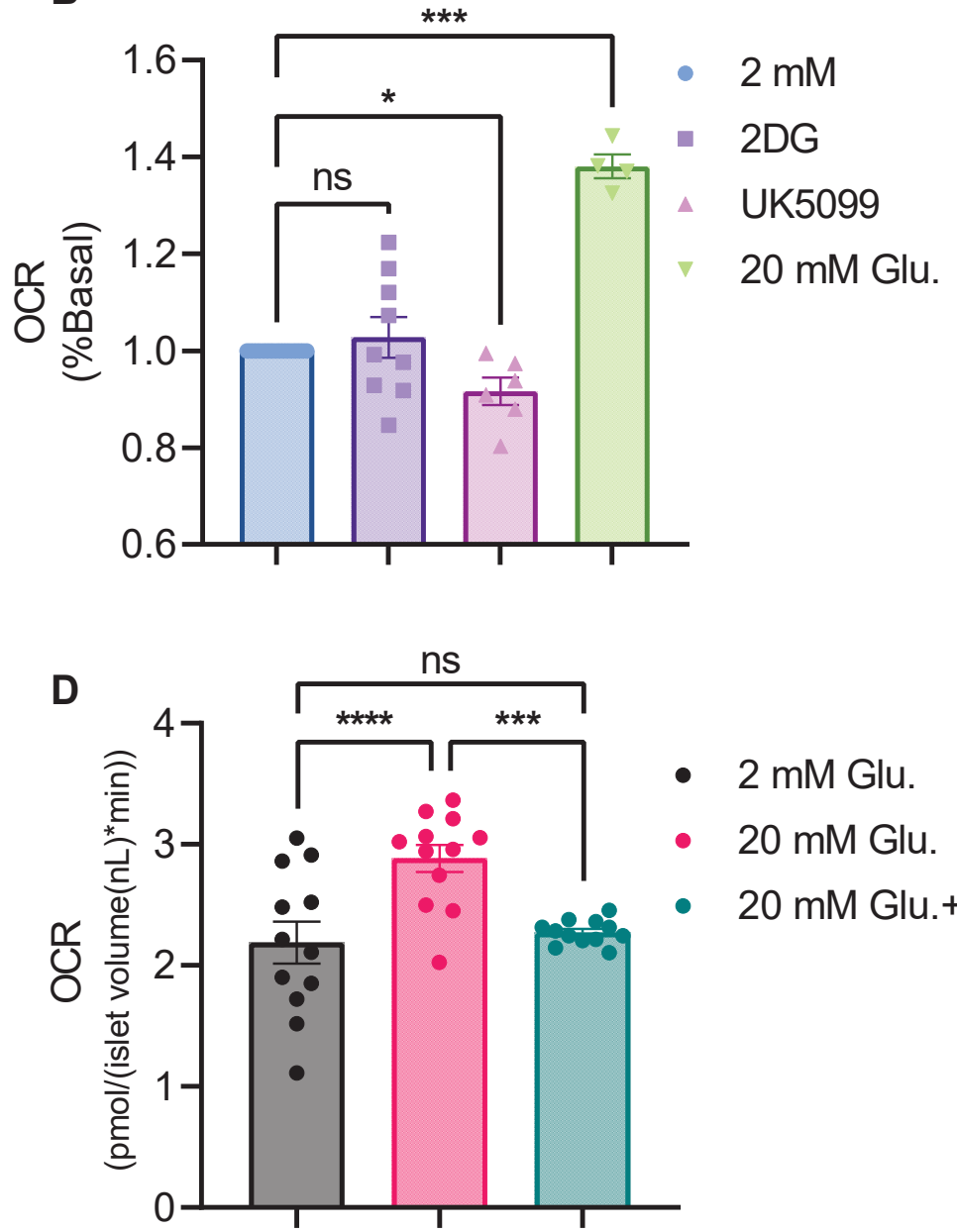

F
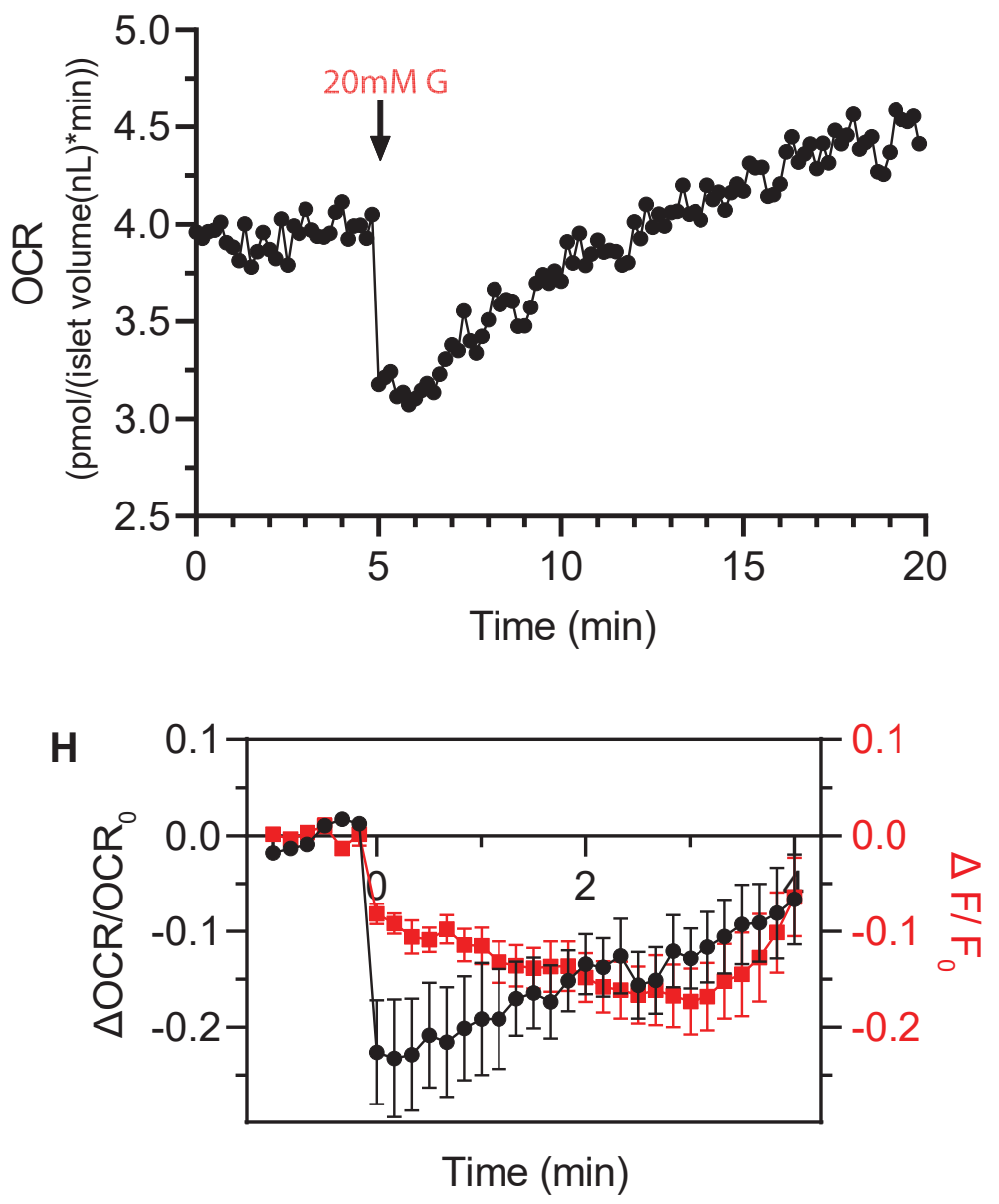

Time $(\min )$
- $2 \mathrm{mM}$ Glu.

- $20 \mathrm{mM}$ Glu.

- $20 \mathrm{mM}$ Glu.+ 2DG

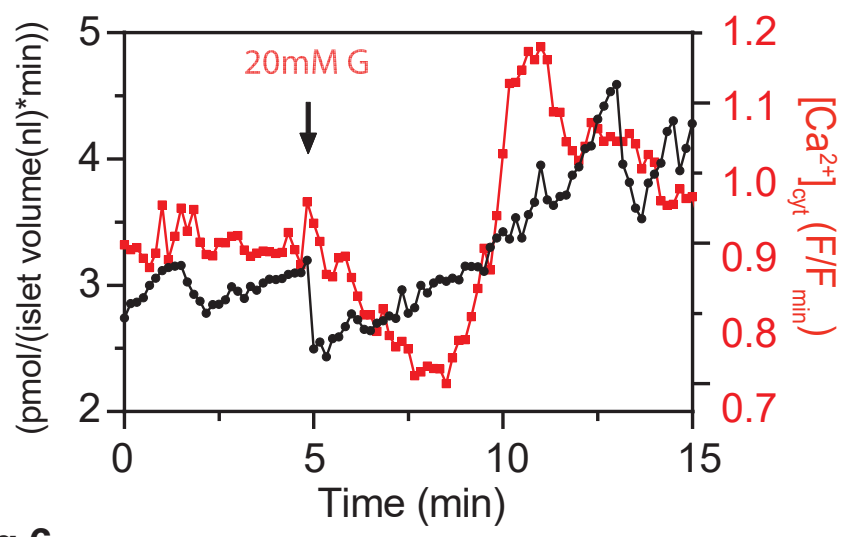


bioRxiv preprint doi: https://doi.org/10.1101/2022.03.02.482671; this version posted March 3, 2022. The copyright holder for this preprint (which was not certified by peer review) is the author/funder, who has granted bioRxiv a license to display the preprint in perpetuity. It is made available under aCC-BY-NC-ND 4.0 International license.

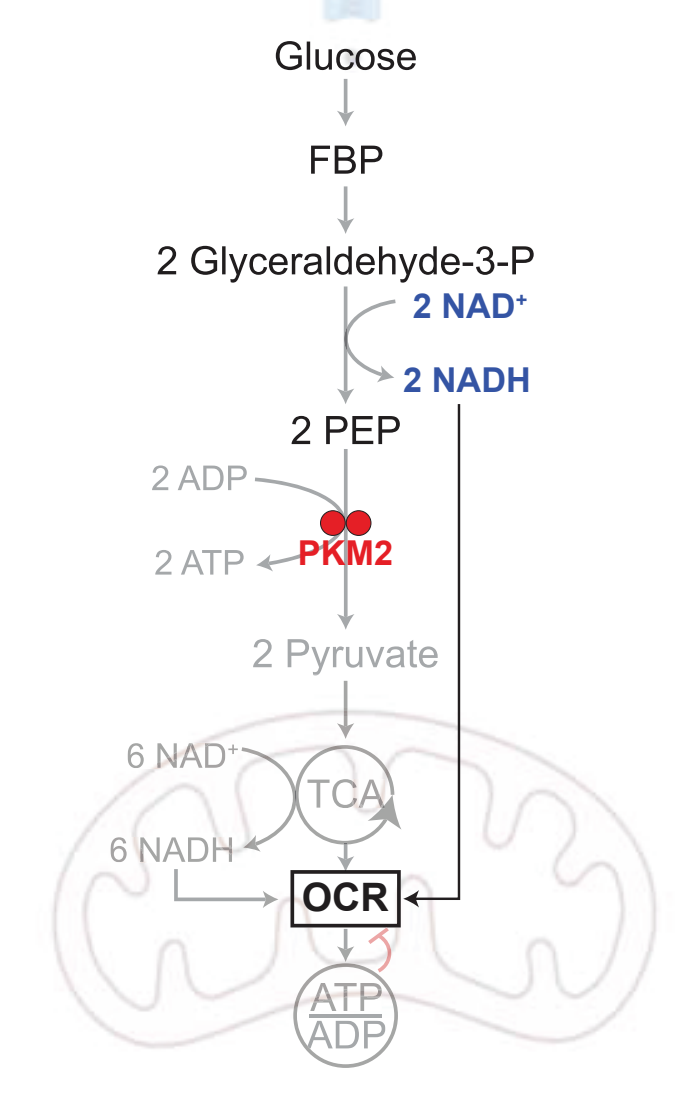

A

(B)

ช

$20 \mathrm{mM}$ Glu.

.

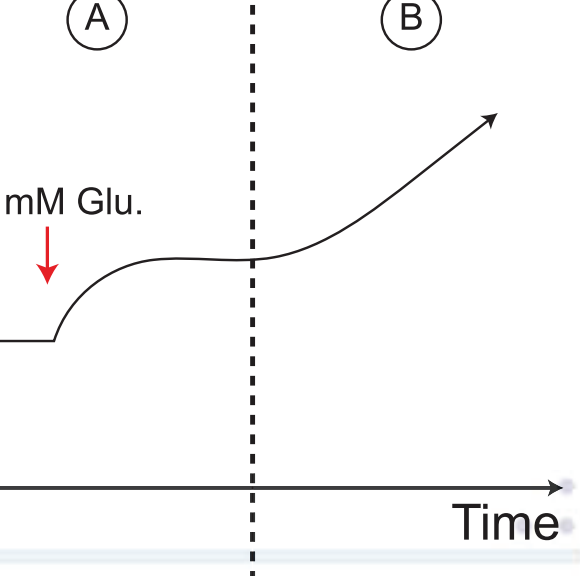

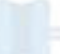

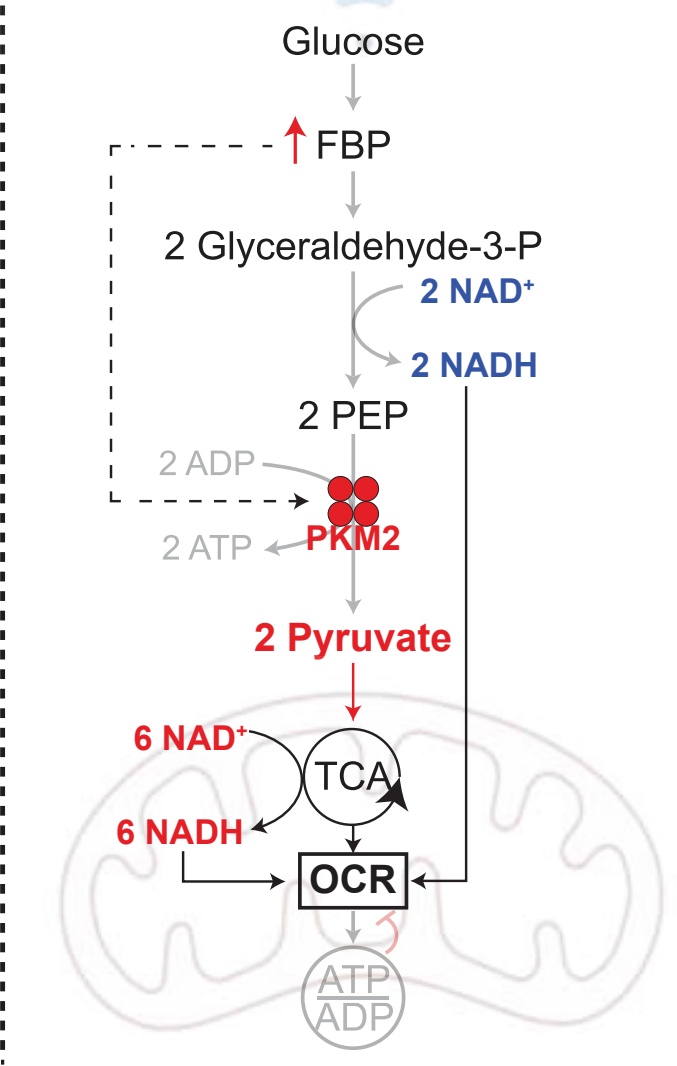

Fig 7 